\title{
Numerical and Experimental Studies of a Light-Weight Auxetic Cellular Vibration Isolation Base
}

\author{
Xiang-Wen Zhang ${ }^{1,2,3}$ and De-Qing Yang ${ }^{1,2,3}$ \\ ${ }^{1}$ State Key Laboratory of Ocean Engineering, Shanghai Jiao Tong University, Shanghai 200240, China \\ ${ }^{2}$ Collaborative Innovation Center for Advanced Ship and Deep-Sea Exploration, Shanghai Jiao Tong University, \\ Shanghai 200240, China \\ ${ }^{3}$ School of Naval Architecture, Ocean and Civil Engineering, Shanghai Jiao Tong University, Shanghai 200240, China \\ Correspondence should be addressed to De-Qing Yang; yangdq@sjtu.edu.cn
}

Received 2 May 2016; Revised 1 August 2016; Accepted 7 August 2016

Academic Editor: Nuno M. Maia

Copyright (c) 2016 X.-W. Zhang and D.-Q. Yang. This is an open access article distributed under the Creative Commons Attribution License, which permits unrestricted use, distribution, and reproduction in any medium, provided the original work is properly cited.

\begin{abstract}
This paper presents a preliminary study of the dynamic performance of a novel light-weight auxetic (negative Poisson's ratio) cellular vibration isolation base constituted by reentrant hexagonal honeycombs. Numerical and experimental analyses were conducted to reveal the effects of Poisson's ratio (cell angle) and relative density (cell thickness) of these reentrant honeycombs on the dynamic performance of this novel base and to propose design guidelines for the best use of the auxetic cellular vibration isolation system. By doing numerical analysis, we found that, by decreasing the relative density of reentrant honeycombs and increasing Poisson's ratio of them, excellent vibration isolation performance of the auxetic cellular base will be achieved. This analysis was followed by static, modal, and frequency response tests, which verified the results of the numerical analysis.
\end{abstract}

\section{Introduction}

It is well known that when most natural materials are stretched in one direction, they contract in the direction transverse to the loading direction, which means they have positive Poisson's ratio. Nonetheless, the classical theory of elasticity does not preclude the existence of materials with negative Poisson's ratio, also known as "auxetic" after 1991 when Evans et al. reelaborated this theory [1]. Auxetic materials/structures present the very unusual property of becoming wider when stretched and narrower when squashed $[2,3]$.

Since Lakes (1993) first transplanted the term of negative Poisson's ratio (NPR) behavior into the field of materials science, the study of auxetic materials and structures has experienced vigorous development [4]. In the past few decades, wide varieties of auxetic materials and structures have been discovered and manufactured, including foams [5, 6], polymers [7-12], composites [13], and metals [14]. Compared with traditional systems, auxetic systems are superior in many practical applications in decreasing the propagation of vibrations efficiently $[15,16]$, exhibiting enhanced indentation resistance [17], presenting an increase in bending stiffness of constructional elements, and so on $[18,19]$. It also has been found that the presence of their auxetic behavior is a scale-independent property; that is, the deformation mechanism can operate at any scale ranging from the nanolevel (molecular level) to the macro-scale [20]. Relevant applications where auxetic systems may be particularly useful are the replacement of blood vessels [21], the fabrication of smart filters and fasteners $[22,23]$, the design of structures with double curvature for aircraft wings and car doors [24], and the production of high quality lifting devices such as helicopter rotor blades [2].

Almost all of the auxetic structures are designed based on this simple mechanism that the global stiffening effects of them are determined by the unit cell $[25,26]$. Over the years, several different units that can achieve auxetic behavior have been proposed, such as reentrant center-symmetric honeycombs $[27,28]$, rotating rectangles and triangles $[29$, $30]$, and arrow-head and star-shaped configurations [31, 32]. Among them, reentrant cellular structure is one of the most classical auxetic structures and has been extensively studied. 


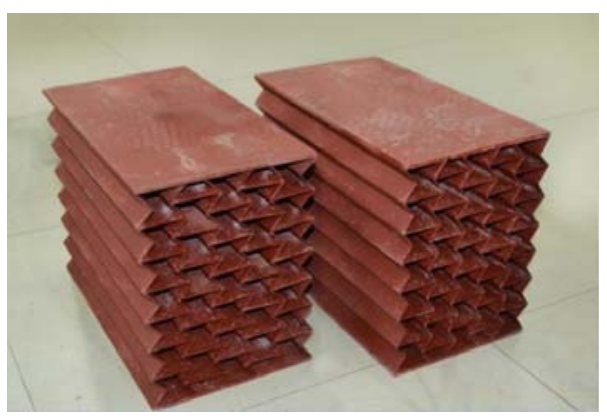

(a)

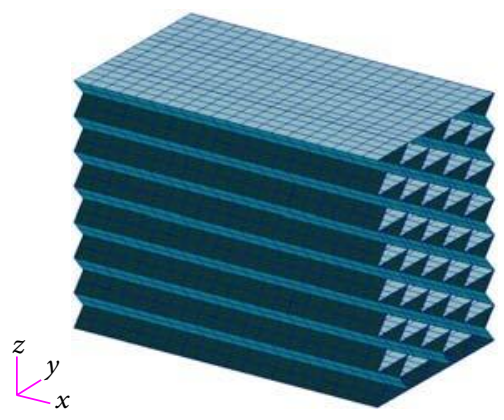

(b)

FIGURE 1: Auxetic cellular vibration isolation base: (a) photo and (b) the FE model.

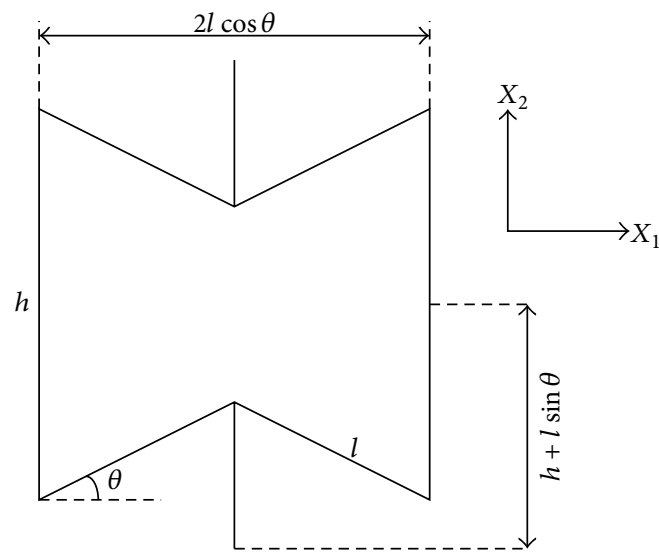

Figure 2: Cell geometry and coordinate system used for the reentrant hexagonal honeycomb, where $h$ is the vertical length of the cell member, $l$ is the inclined length of the cell member, and $\theta$ is the cell angle.

Gibson and Ashby [33], Masters and Evans [34], and Evans et al. [35] are the pioneers working on this structure. Using the geometric configuration and coordinate system of Figure 2, Gibson et al. indicated that reentrant cellular structures have negative Poisson's ratio when an external load is given to it $[33,36]$.

This paper is designed to study the dynamic performance of a light-weight vibration isolation base made of the foldable (the aspect ratio of honeycombs is 2), equal-height reentrant hexagonal honeycombs. By changing the geometry of the reentrant honeycombs, the novel auxetic cellular base will take on a tunable negative Poisson's ratio and it is much lighter than traditional bases, while the load bearing capability is the same. This study focuses on the effect of the geometric parameters (cell angle and thickness) of the reentrant honeycombs on the vibration reduction performance of the base. Finite element method was used as the modelling technique to analyze the dynamic performance of the base. Both numerical analysis and experiments were conducted, which turned out to be in good agreement with each other.

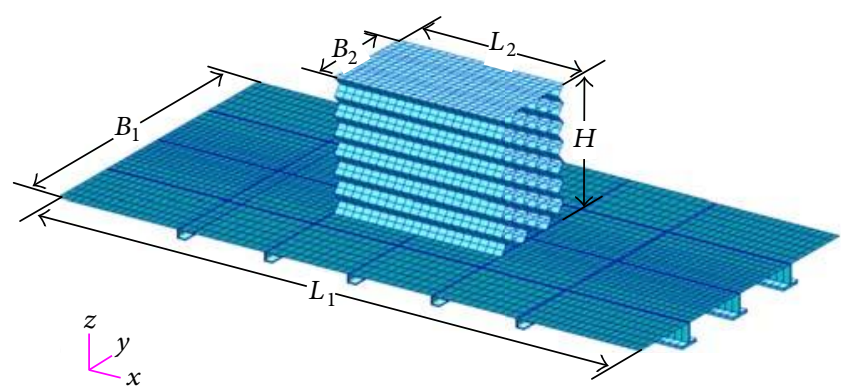

Figure 3: Disposition of the auxetic cellular vibration isolation system, where $B_{1}=710 \mathrm{~mm}, L_{1}=1400 \mathrm{~mm}, L_{2}=400 \mathrm{~mm}$, and $H=300 \mathrm{~mm}\left(B_{2}\right.$ is affected by the vertical length of the reentrant honeycomb).

\section{Effects of Parameters on Vibration Reduction Performance of the Auxetic Cellular Base}

2.1. Auxetic Cellular Base. The novel auxetic cellular vibration isolation base proposed in this paper, as shown in Figure 1, is made of seven-layer, five-row honeycombs with the cell angle within the range $-45<\theta<0^{\circ}$. For a constant cell height $2 l \cos \theta=42.86 \mathrm{~mm}$, the vertical length $h$ and the inclined length $l$ vary with the cell angle $\theta$, when the aspect ratio of honeycombs $h / l$ is 2 (refer to Figure 2 ). The auxetic cellular vibration isolation system, which consists of the auxetic cellular base and a steel grillage supporting the base, is shown in Figure 3. The thickness of the plates of both the base and the grillage is $6 \mathrm{~mm}$ and the grillage is reinforced by $20 \times 3$ angle steel and $50 \times 50 \times 5 \times 7 \mathrm{~T}$-stub steel. We assumed that the grillage is simply supported on four edges and the load is laid along the $Z$ direction. Weights of the presented auxetic cellular vibration isolation base and the machinery device are $25.73 \mathrm{~kg}$ and $500 \mathrm{~kg}$, respectively. Standard Quad4 element type was used to model the behavior of the system. The maximum size of the element was $10 \mathrm{~mm} \times 15 \mathrm{~mm}$ and the minimum was $3 \mathrm{~mm} \times 3 \mathrm{~mm}$. The finite element model of the presented vibration isolation system was built using software MSC Patran with 9257 elements. 


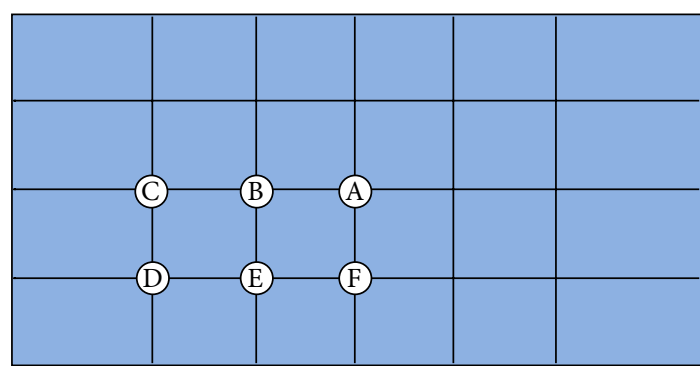

FIGURE 4: Layout of measuring points.

A variety of methods can be used to evaluate the performance of vibration isolation systems, such as the insertion loss of forces or responses and the vibration level difference [37]. In this paper, we applied acceleration vibration level difference to evaluate the structural dynamics behavior of the auxetic cellular base, not only for the convenience of measure, but also for the decrease of error. Six measuring points were arranged under the grillage, where the boundary layer effects were negligible in view of the specimen dimensions, as shown in Figure 4. Acceleration responses of the measuring points were obtained through the frequency response analysis using MSC Nastran software.

On the basis of cellular material theory [33], the relative density $\left(\rho / \rho_{s}\right.$, where $\rho_{s}$ is the density of solid materials) and Poisson's ratio $\left(\nu_{21}\right)$ of auxetic cellular materials can be calculated as follows (refer to Figure 2):

$$
\begin{aligned}
\frac{\rho}{\rho_{s}} & =\frac{t / l(h / l+2)}{2 \cos \theta(h / l+\sin \theta)}, \\
v_{21} & =-\frac{\varepsilon_{1}}{\varepsilon_{2}}=\frac{\cos ^{2} \theta}{(h / l+\sin \theta) \sin \theta} .
\end{aligned}
$$

As to the foldable (the aspect ratio of honeycombs is 2), equal-height reentrant hexagonal honeycombs, Poisson's ratio of auxetic cellular materials/structures changes with the cell angle (Figure 5) and, similarly, relative density can be altered by changing the cell thickness and cell angle, according to (1) and (2). Furthermore, when $t / l$ is fixed, the relative density as a function of cell angle can be plotted in Figure 6.

As illustrated in Figure 5, Poisson's ratio decreases with the increase of the cell angle. It decreases slowly between 0 and -1 when the cell angle magnitude is larger than $30^{\circ}$ and then decreases dramatically when the cell angle magnitude is lower than $30^{\circ}$. Moreover, Figure 6 suggests that, for a certain cell thickness, decreasing the magnitude of the cell angle is accompanied by the decrease of the relative density. Furthermore, it can be observed from (1) that, by fixing the honeycomb geometry, increasing the cell thickness leads to the increase of the relative density.

2.2. Effect of Poisson's Ratio. The effect of Poisson's ratio on the vibration isolation performance of the auxetic cellular base is shown in Figure 7. When the cell thickness is kept constant, we found that the curves can be divided into two

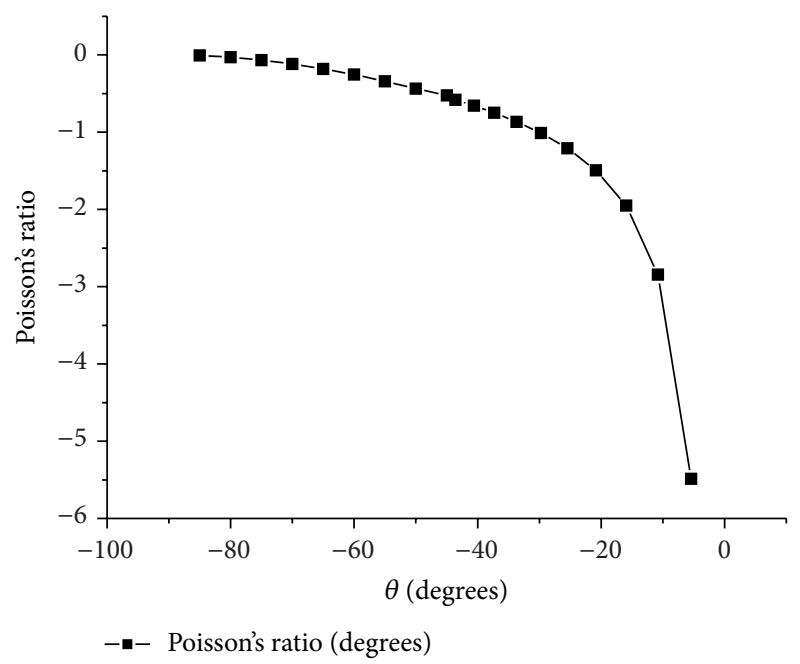

FIGURE 5: $v_{21}$ versus $\theta$ calculated from (2) for equal-height cells, where $h / l=2,2 l \cos \theta=42.86 \mathrm{~mm}$, and $t=1 \mathrm{~mm}$.

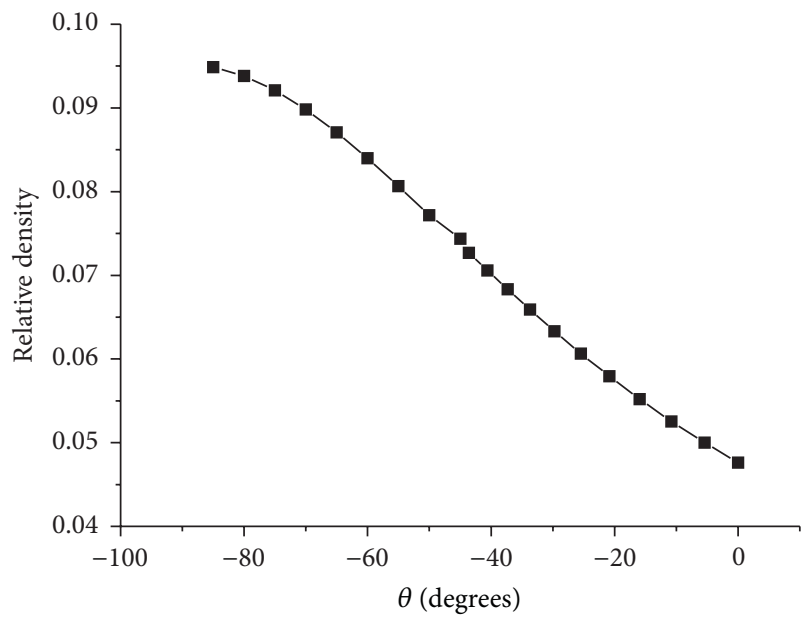

FIGURE 6: $\rho / \rho_{s}$ versus $\theta$ calculated from (1) for equal-height cells, where $h / l=2,2 l \cos \theta=42.86 \mathrm{~mm}$, and $t=1 \mathrm{~mm}$.

stages: when Poisson's ratio is lower than -3 , the acceleration vibration level difference remains nearly constant; after that, it grows at an exponential rate. From this tendency, we can get fitting curves from different models and the function expression is written as (3). Parameters of the function and correlation coefficients ( $R$-square) between the numerical simulation results and (3) are listed in Table 1. In all cases, each fitting curve has a large correlation coefficient, ranging from 0.9884 to 0.9977 , which shows the remarkable accuracy of the function expression. It also can be seen in Figure 7 that auxetic cellular base with small cell thickness is more sensitive to Poisson's ratio of the honeycombs. When the cell thickness increases to $4 \mathrm{~mm}$ from $1 \mathrm{~mm}$, the vibration level difference increases slightly, by about 32\%, with Poisson's ratio in the range $-5<v<0$. Such a behavior was expected based on the theoretical considerations of the stiffness of models. For the same geometric parameters of honeycombs, the thinner the cell thickness is, the smaller the stiffness and the larger 

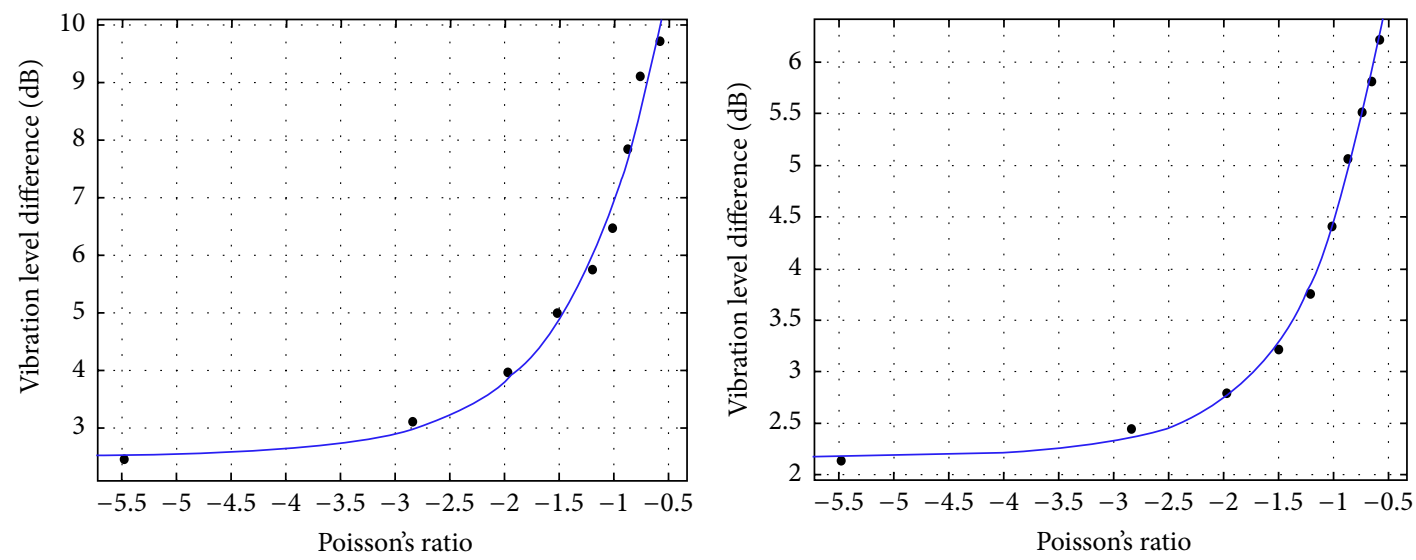

- $t=1 \mathrm{~mm}$

- $t=1.5 \mathrm{~mm}$

- Fit curve

(a)
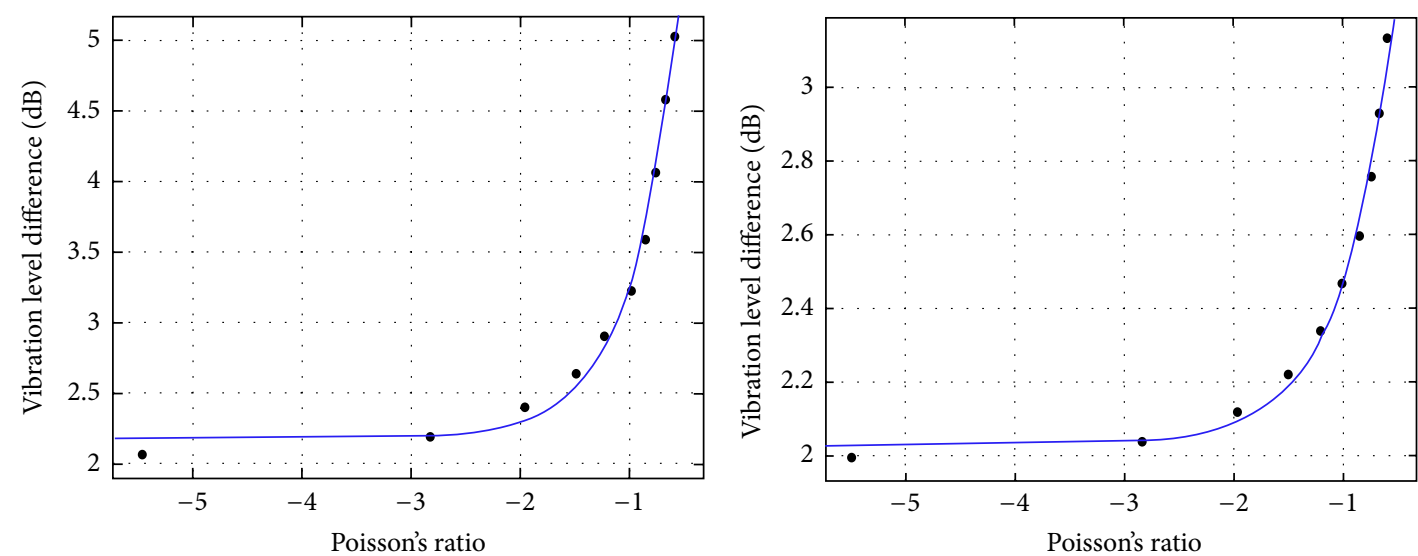

- $t=2 \mathrm{~mm}$

- $t=3 \mathrm{~mm}$

Fit curve

(c)

(d)

Fit curve

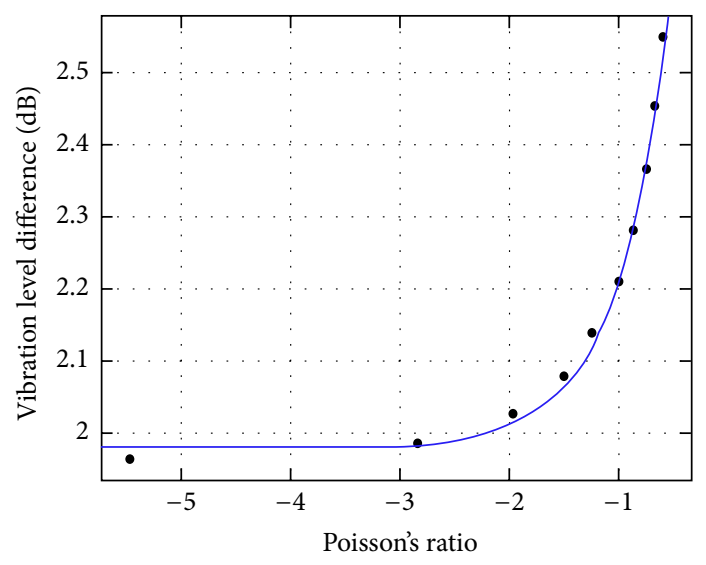

- $t=4 \mathrm{~mm}$

Fit curve

(e)

FIGURE 7: Acceleration vibration level difference of auxetic cellular base variation against Poisson's ratio for different values of the cell thickness: (a) $t=1 \mathrm{~mm}$, (b) $t=1.5 \mathrm{~mm}$, (c) $t=2 \mathrm{~mm}$, (d) $t=3 \mathrm{~mm}$, and (e) $t=4 \mathrm{~mm}$. 
TABLE 1: Parameters of the function expression.

\begin{tabular}{lcccc}
\hline Cell thickness $(\mathrm{mm})$ & $A$ & $B$ & $C$ & $R$-square \\
\hline$t=1$ & 15.31 & -1.248 & 2.532 & 0.9884 \\
$t=1.5$ & 9.392 & -1.43 & 2.197 & 0.9971 \\
$t=2$ & 10.26 & -2.234 & 2.18 & 0.9951 \\
$t=3$ & 3.532 & -2.057 & 2.028 & 0.9954 \\
$t=4$ & 1.818 & -2.037 & 1.98 & 0.9977 \\
\hline
\end{tabular}

the responses of the system will be. The auxetic thin-walled base is more like a spring vibration isolator and its stiffness coefficient is affected by the cell angles. For the foldable equalheight honeycombs, Poisson's ratio is the main influence factor of the stiffness coefficient. As Poisson's ratio increases in the range $-1<v<0$, vibration level difference decreases with the increase of the cell thickness. Moreover, although the smaller cell thickness is, the more suitable it is for the base design, decreasing the cell thickness cannot significantly improve the vibration isolation performance of the auxetic cellular base when Poisson's ratio of the honeycombs is lower than -1 ,

$$
\operatorname{VLD}(\nu)=A e^{-B \nu}+C .
$$

2.3. Effect of the Relative Density. Figure 8 shows the effect of the relative density of the honeycombs on the vibration isolation performance of the auxetic cellular base. In the first place, contrary to the effect of Poisson's ratio, the vibration level difference of the auxetic cellular base decreases with the increase of the relative density when the cell angle is kept constant. In the second place, along with the increase of values of the relative density, vibration level difference increases when the cell thickness is kept constant. For a big value of the cell thickness (like $4 \mathrm{~mm}$ or larger), however, the change of the relative density has nearly no effect on the vibration level difference of the base. We can also find in Figure 8 that the vibration isolation performance of the novel auxetic cellular base is much more sensitive to the relative density of honeycombs when the cell thickness is small and the cell angle magnitude is large.

Therefore, according to Sections 2.2 and 2.3, we drew a preliminary conclusion that the novel auxetic cellular base achieves better vibration isolation performance with the decrease of relative density and the increase of Poisson's ratio of reentrant honeycombs.

2.4. Vibration Isolation Optimization Design. As described above, the vibration isolation performance of the auxetic cellular base is affected by various parameters of reentrant honeycombs. In order to find the optimum shape and size of the honeycombs, we proposed an optimization model through software Optistruct, which can be expressed as (4). The minimum mass of reentrant honeycombs was defined as the optimization objective, with the cell thickness $(t)$ and the cell angle $(\theta)$ as design variables. The initial value of the cell thickness was $2 \mathrm{~mm}$, while the cell angle varied from $0^{\circ}$ to $-45^{\circ}$. The maximum structural stress $\left(\sigma_{\max }\right)$ and the minimum vibration level difference $\left(\mathrm{VLD}_{\min }\right)$ were

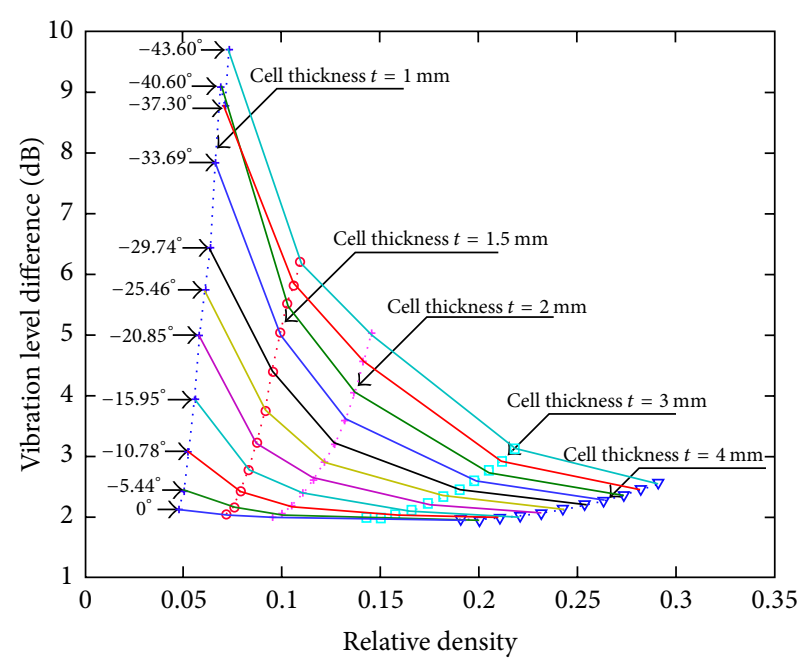

FIGURE 8: Acceleration vibration level difference of auxetic cellular base variation against the relative density.

selected as constraints for the requirements of safety and dynamic performance, and their magnitudes were $150 \mathrm{MPa}$ and $6 \mathrm{~dB}$, respectively. The calculation processes and results of the optimization objective, design variables, and constraint conditions are shown in Figure 9:

$$
\begin{array}{cl}
\text { Find } & t, \theta \\
\text { Min } & \text { Mass } \\
\text { s.t. } & \mathrm{VLD} \geq \mathrm{VLD}_{\min } \\
& \sigma_{i} \leq \sigma_{\max }, \quad(i=1,2, \ldots, n) \\
& 1 \leq t \leq 5 \mathrm{~mm}, \\
& -45 \leq \theta \leq 0^{\circ},
\end{array}
$$

where $n$ is the number of elements.

The results indicate that, by optimizing the cell thickness and the cell angle, the value of the vibration level difference has increased by nearly five times, from $1.9 \mathrm{~dB}$ to $9.52 \mathrm{~dB}$ compared with the initial model, while the mass of reentrant honeycombs decreased by $5 \mathrm{~kg}$. The optimal values of the cell thickness and cell angle are $1 \mathrm{~mm}$ and $-45^{\circ}$, respectively. It is worth pointing out that these results also show good agreement with those of the FEM models discussed earlier, which proves that, by decreasing relative density and increasing Poisson's ratio of reentrant honeycombs, the auxetic cellular base displays better vibration isolation performance.

For a traditional $500 \mathrm{~kg}$ class vibration isolation base, it usually contains three parts: face plates, web plates, and brackets, as shown in Figure 10. The thicknesses of these three parts are $10 \mathrm{~mm}, 8 \mathrm{~mm}$, and $8 \mathrm{~mm}$, respectively. With the same conditions as the auxetic one presented in this paper, the frequency response analysis of it was done. The results of the analysis and the comparison of the two bases are listed in Table 2. It can be seen that the weight of the traditional base is four times the auxetic base. Its vibration level difference, however, is only half of the auxetic one. This is not an individual case. In general, there are three types of vibration 


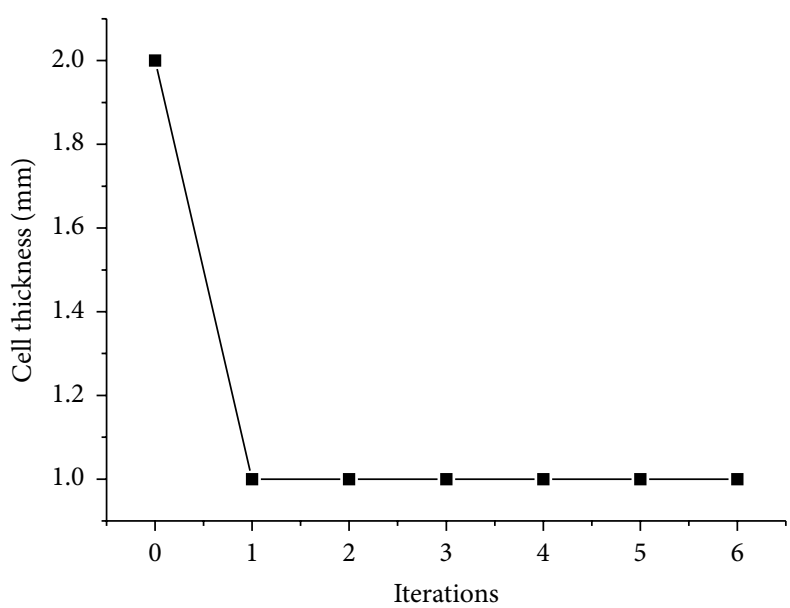

(a)

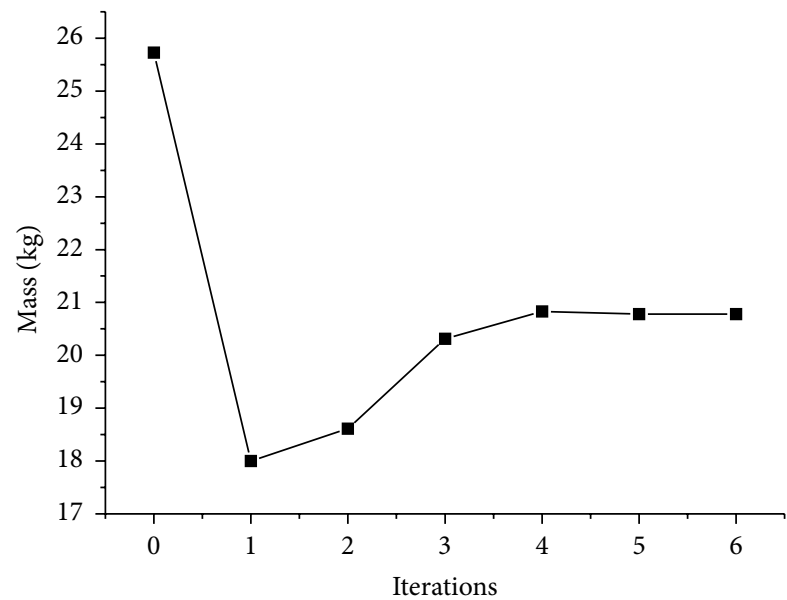

(c)

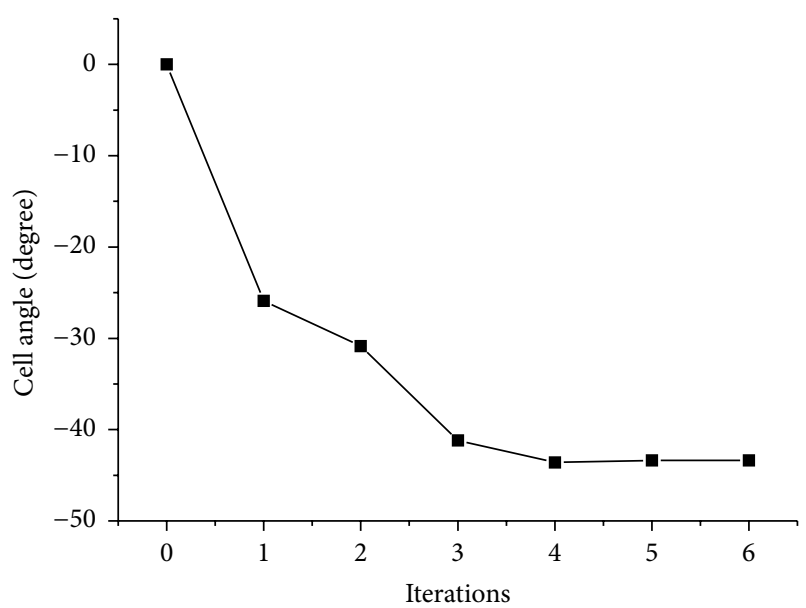

(b)

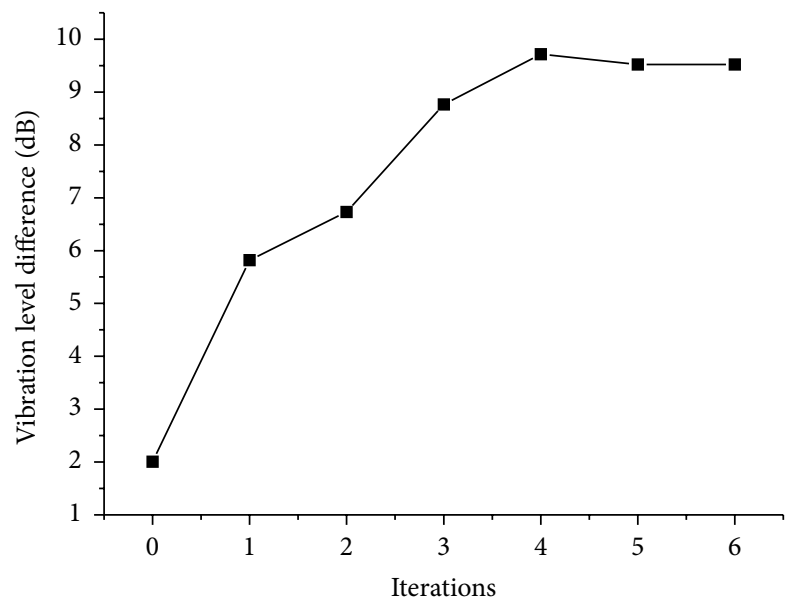

(d)

FIGURE 9: Iteration curve of (a) cell thickness, (b) cell angle, (c) mass of honeycombs, and (d) vibration level difference.

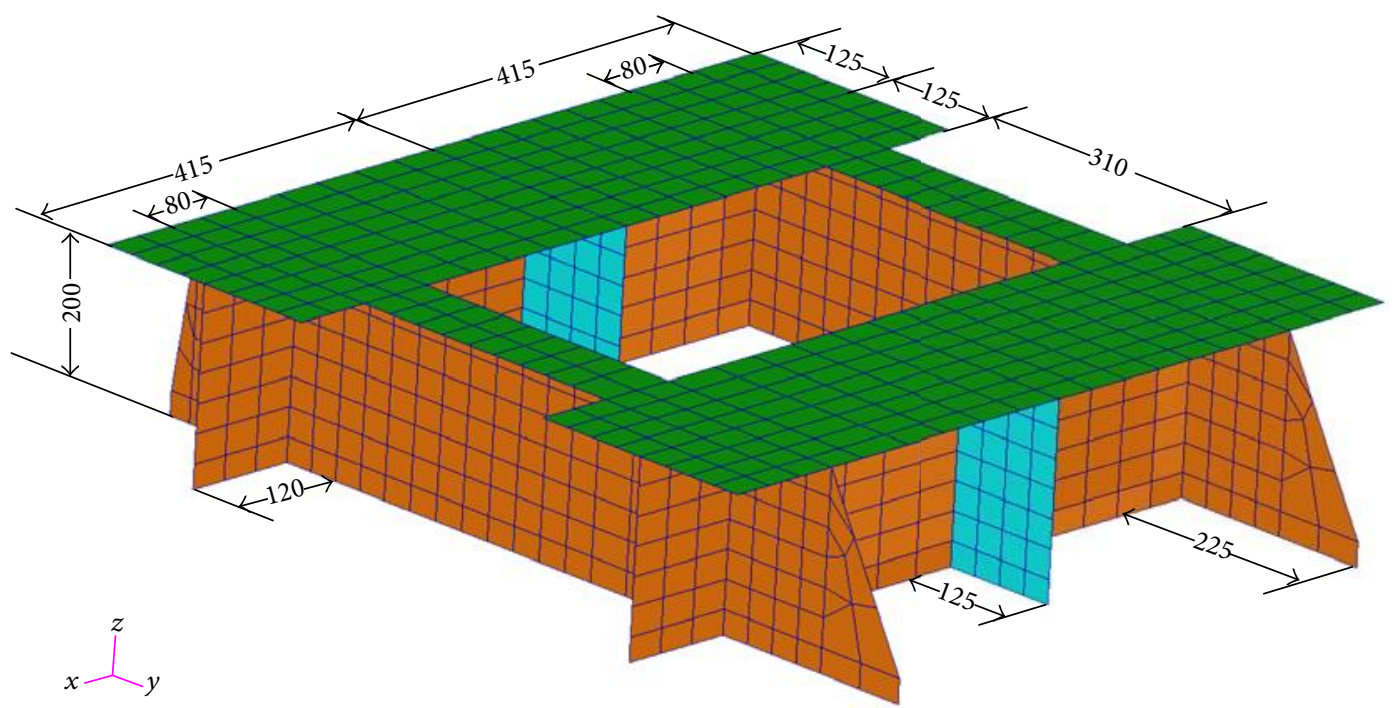

FIGURE 10: Traditional $500 \mathrm{~kg}$ class vibration isolation base, where the green parts are face plates, the brown parts are web plates, and the blue parts are brackets. 


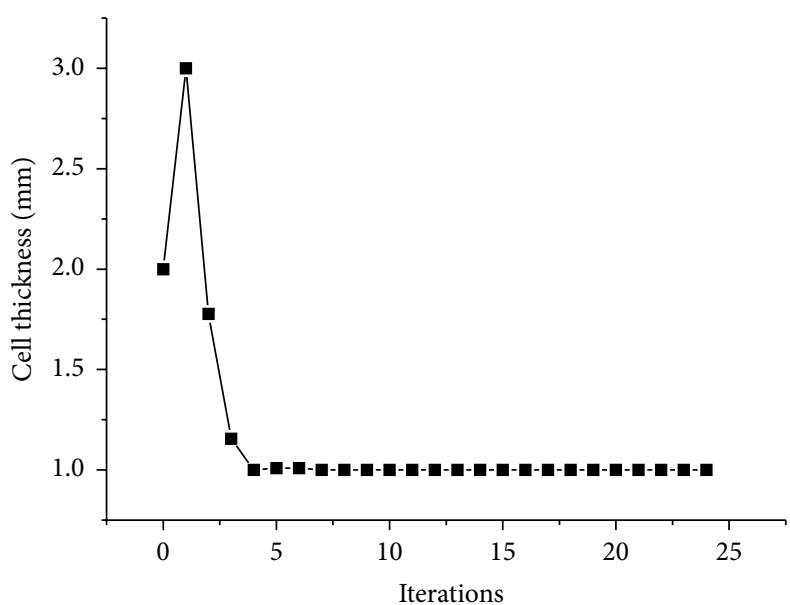

(a)

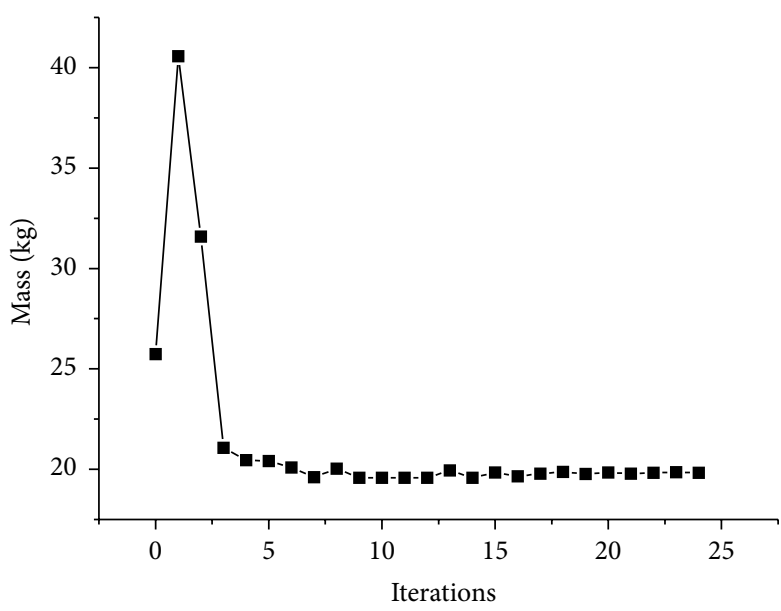

(c)

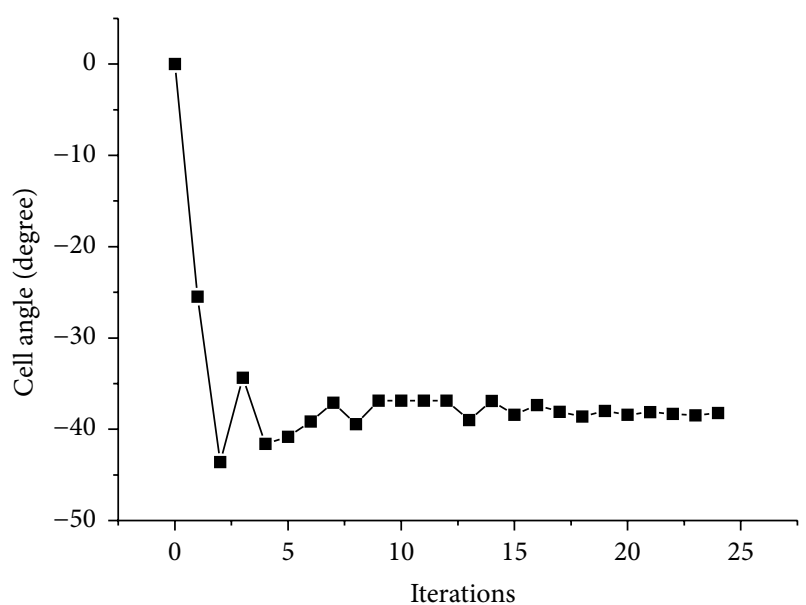

(b)

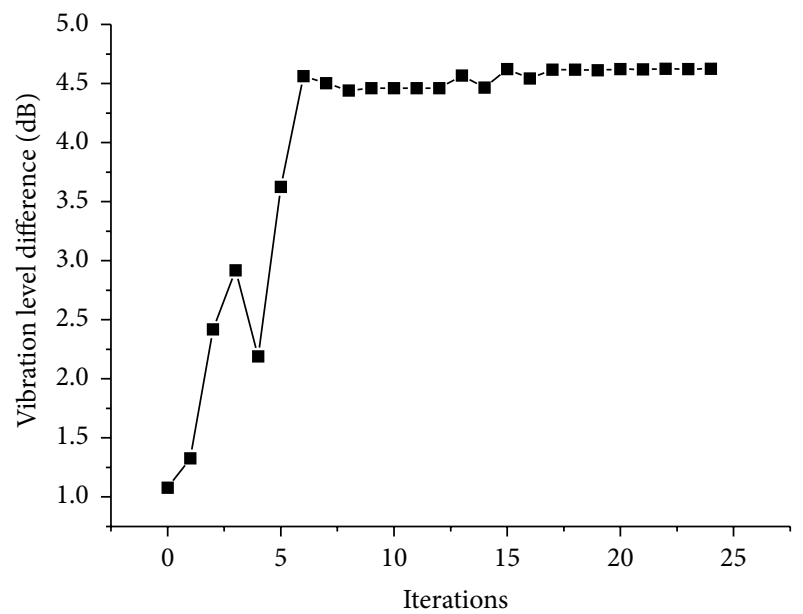

(d)

FIGURE 11: Iteration curve of (a) cell thickness, (b) cell angle, (c) mass of honeycombs, and (d) vibration level difference.

isolation systems: single-stage system, two-stage system, and floating raft isolation system. The stability and the vibration isolation performance of the single-stage system are poor and what is worse, the system often vibrates in resonance with the exciting source in the high frequencies. As for two-stage system and floating raft isolation system, in order to obtain the good performance, the additional mass is needed, which greatly increases the weight of the system. Compared with those traditional bases, the vibration isolation performance of the auxetic cellular vibration isolation base can be adjusted by many parameters, such as cell angle and cell thickness. We could also apply the optimization method mentioned above to improve the performance. And most important of all, it does not need any additional mass and with the porous structure, the weight of itself is very light. As a result, the presented auxetic cellular base possesses a broad scope in the vibration isolation field.

\section{Experimental Verification and Discussion}

3.1. Model Description. For convenience of experiment, in this section, we put forward a new numerical simulation
TABLE 2: Comparison of the two bases.

\begin{tabular}{lcc}
\hline & $\begin{array}{c}\text { Acceleration vibration } \\
\text { level difference }(\mathrm{dB})\end{array}$ & Weight $(\mathrm{kg})$ \\
\hline Auxetic cellular base & 9.52 & 20.7 \\
Traditional base & 5.67 & 84.1 \\
\hline
\end{tabular}

model with simpler boundary conditions and a lighter machinery device $(25 \mathrm{~kg})$ : the grillage was no more simply supported on four edges, but on two edges along the $Y$ direction (refer to Figure 3). We still used (4) to seek the optimum results of this new model. What is different from the previous optimization model is that the constraint condition of the minimum vibration level difference $\left(\mathrm{VLD}_{\min }\right)$ changed from $6 \mathrm{~dB}$ to $3 \mathrm{~dB}$, considering the weakening of boundary conditions. The calculation processes and results of the optimization objective, design variables, and constraint conditions in this situation are shown in Figure 11.

Along with the increase of iterative steps, the cell thickness increases slightly and then drops abruptly to the minimum value. After the fluctuation, the cell angle also 
TABLE 3: Comparison of different optimal models ${ }^{*}$.

\begin{tabular}{lcccccccc}
\hline & \multicolumn{2}{c}{ Relative density } & \multicolumn{2}{c}{ Poisson's ratio } & \multicolumn{2}{c}{ Mass $(\mathrm{kg})$} & \multicolumn{2}{c}{$\begin{array}{c}\text { Vibration level difference } \\
(\mathrm{dB})\end{array}$} \\
& $\begin{array}{c}\text { Initial } \\
\text { parameter }\end{array}$ & $\begin{array}{c}\text { Optimal } \\
\text { results }\end{array}$ & $\begin{array}{c}\text { Initial }^{* *} \\
\text { parameter }\end{array}$ & $\begin{array}{c}\text { Optimal } \\
\text { results }\end{array}$ & $\begin{array}{c}\text { Initial } \\
\text { parameter }\end{array}$ & $\begin{array}{c}\text { Optimal } \\
\text { results }\end{array}$ & $\begin{array}{c}\text { Initial } \\
\text { parameter }\end{array}$ & $\begin{array}{c}\text { Optimal } \\
\text { results }\end{array}$ \\
\hline Model 1 & 0.095 & 0.074 & - & -0.547 & 25.73 & 20.73 & 1.9 & 9.52 \\
Model 2 & 0.095 & 0.069 & - & -0.723 & 25.73 & 19.82 & 1.1 & 4.62 \\
\hline
\end{tabular}

${ }^{*}$ Model 1 is simply supported on four edges and the weight of the machinery device is $500 \mathrm{~kg}$. Model 2 is simply supported on two edges and the weight of the machinery device is $25 \mathrm{~kg}$.

${ }^{* *}$ The initial cell angle of the optimal model is $0^{\circ}$ which means the cell is not a reentrant honeycomb anymore.

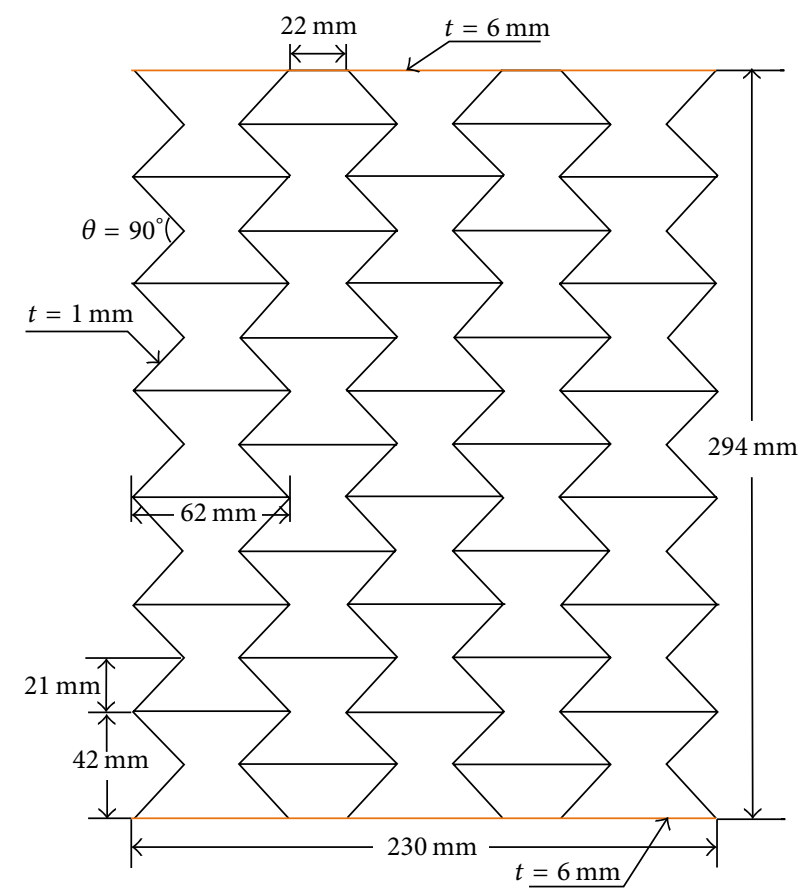

(a)

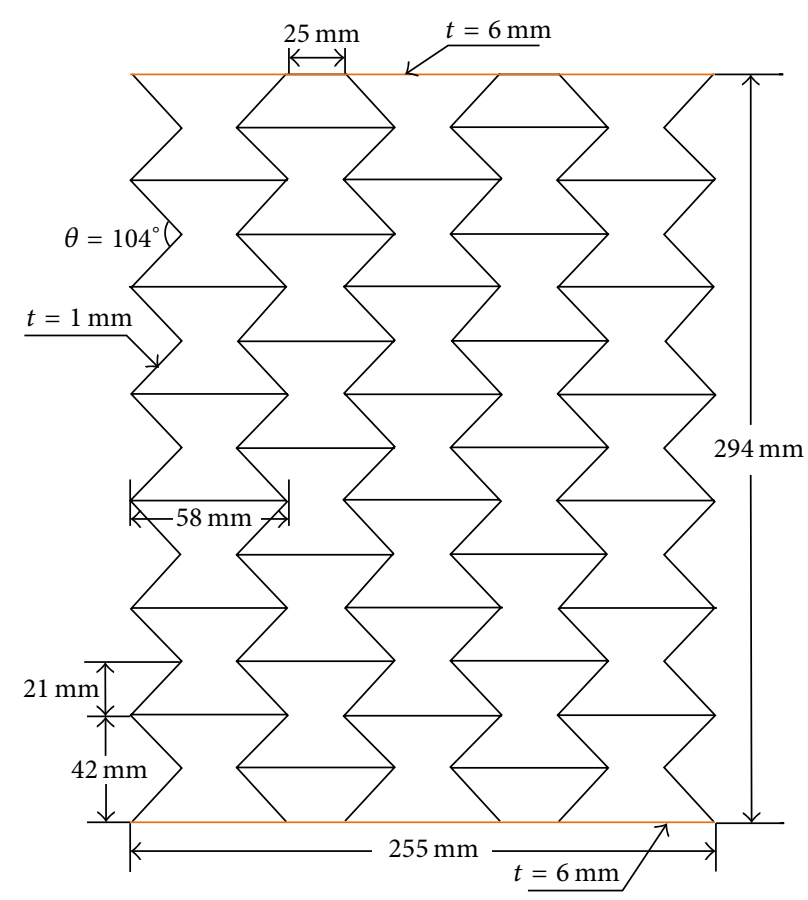

(b)

Figure 12: Geometry of two test bases: (a) the control base and (b) the verification base.

reaches the optimal value of $-38.2^{\circ}$. By optimizing the cell thickness and the cell angle, the magnitude of the vibration level difference has increased by four times, from $1.1 \mathrm{~dB}$ to $4.62 \mathrm{~dB}$; meanwhile the mass of the reentrant honeycombs has decreased by $5.91 \mathrm{~kg}$. When values of $t$ and $\theta$ are $1 \mathrm{~mm}$ and $-45^{\circ}$, respectively, the vibration level difference of the auxetic cellular base is $2.93 \mathrm{~dB}$. The optimal models and results of shape and size of the auxetic cellular base were presented in Table 3. From the comparison of the two numerical simulation models, the following assumptions are made: besides the geometric parameters, boundary conditions also play an important role in the vibration isolation performance of the auxetic cellular base, which will benefit from strong constraints. Furthermore, the comparison also proves that the optimal model is feasible for different boundary conditions.

In order to do a validation analysis of the optimal model and results, we tested two auxetic cellular bases marked as verification base and control base in Figures 1 and 12. The parameters of the verification base are consistent with the optimal results, while the control base has a cell angle of $-45^{\circ}$. Considering the installation conditions, we also made a bigger steel grillage (Figures 13 and 14) with the same positions of measuring points in Figure 4. The experimental tests have been conducted at the Engineering Mechanics Experimental Center of Shanghai Jiao Tong University.

3.2. Statics Test. The two auxetic cellular bases were fixed on the test bench and different weights were first put on and then removed from the upper faceplate of the base with the displacements measured by a laser displacement meter (KEYENCE, LK-G5001), as shown in Figure 15. Typical displacement-weight curves of the two bases obtained from the experiment are shown in Figure 16. It can be seen that, in the process of adding and reducing the weights, both of the two bases show good linear elastic properties. It also shows that the gradient of the curve in Figure 16(a) is bigger than 


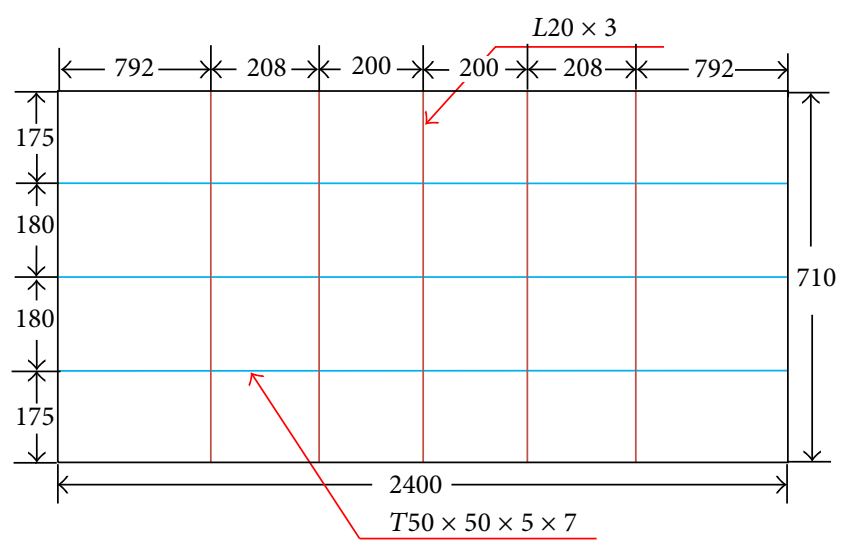

FIGURE 13: Geometry of the steel grillage.

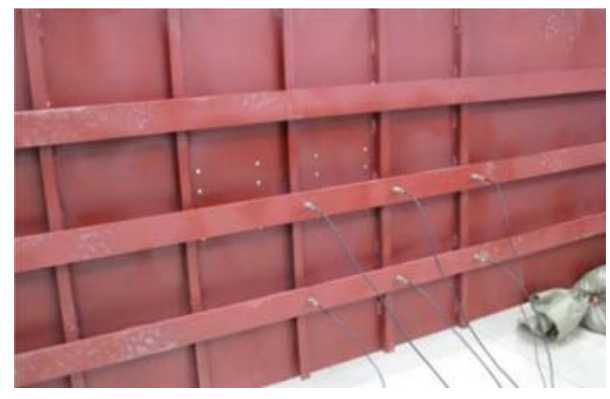

FIGURE 14: Photo of the steel grillage and measuring points.

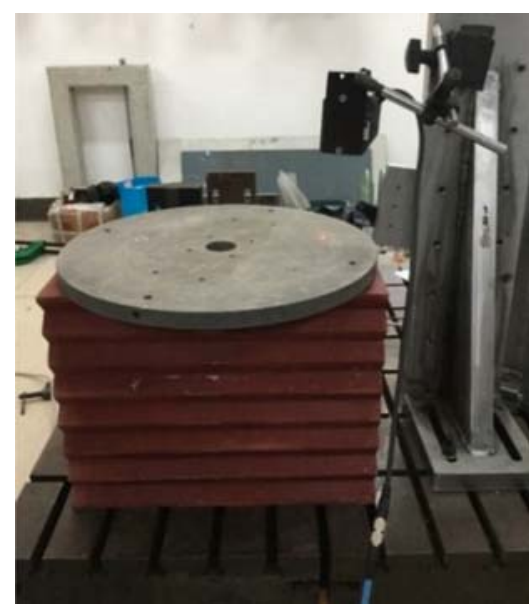

FIGURE 15: Statics experiment of the auxetic cellular base.

that in Figure 16(b), which means the vertical elastic stiffness of the verification base is bigger than that of the control base. This can be attributed to the different cell angles of honeycombs between the two bases.

3.3. Modal Test. Modal test was done to analyze the dynamic characteristics of the two bases. Through the modal test, the natural frequencies of the bases within a given frequency range can be obtained. The main instruments used are a signal generator (B\&K 1027), a power amplifier (ECON,

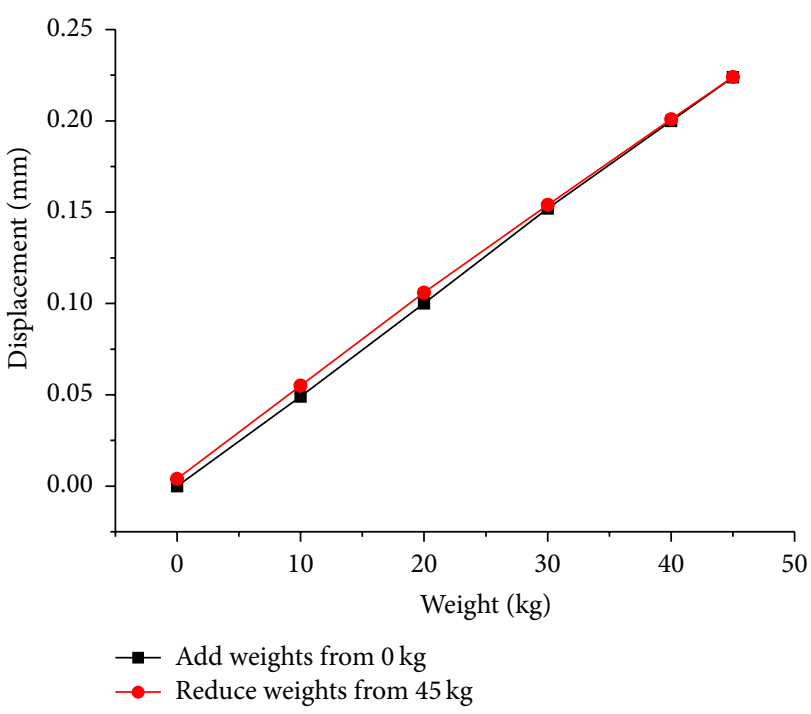

(a)

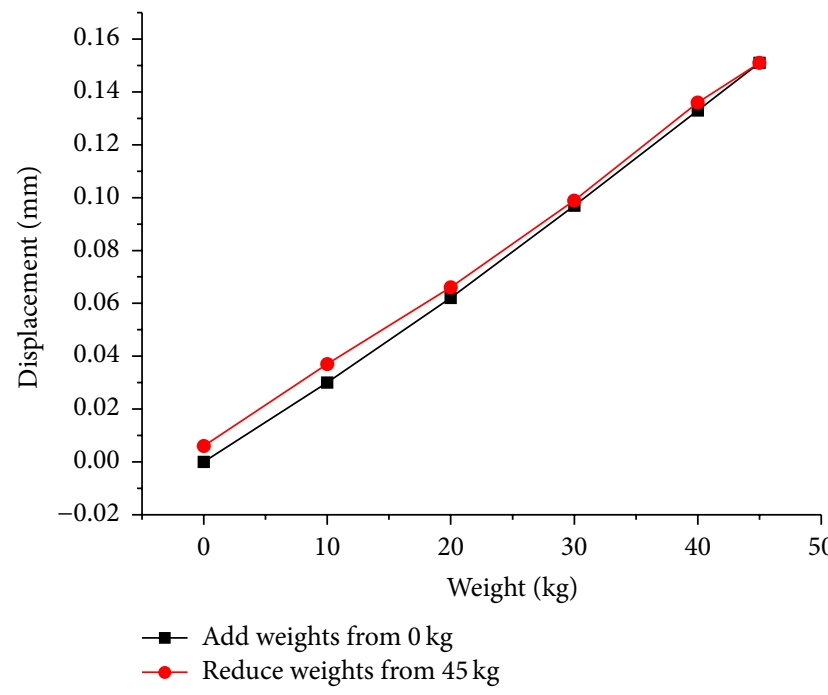

(b)

FIGURE 16: Displacement-weight curve for two bases: (a) the control base and (b) the verification base.

MI-2004), an electrodynamic shaker (Labworks Inc., ET 139), a laser sensor (Polytec, PSV-300F), and a DASP signal acquisition card (DH5920N). Sandbags and $\Phi 77 \mathrm{~mm}$ round steel were used to simulate boundary conditions, as shown in Figure 17. In consideration of the symmetry of the system, we arranged measuring points for laser in half of the structure (Figure 18). The bases were loaded vertically and vertical natural frequencies of the auxetic cellular base and the steel grillage were observed within the $0-500 \mathrm{~Hz}$ frequency bandwidth. The fundamental vertical vibration mode shapes and average velocity response functions of the two bases are shown in Figures 19-22. Depending on these results, constraint conditions and damping coefficient of the original numerical simulation models were modified. For example, by modifying the constraint boundaries of the numerical models, the effect of the position and the weight of the 


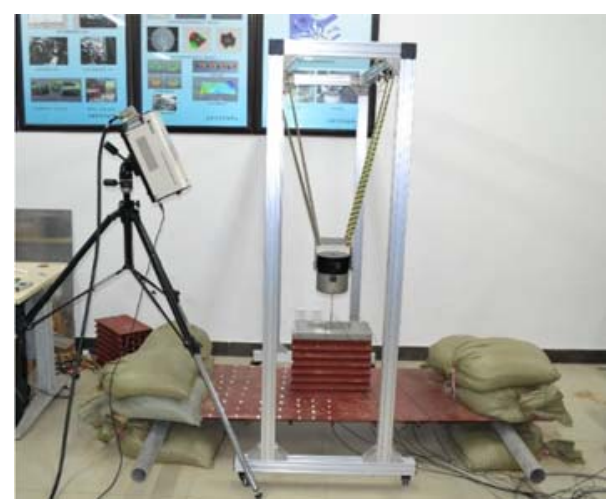

Figure 17: Modal test of the auxetic cellular base.

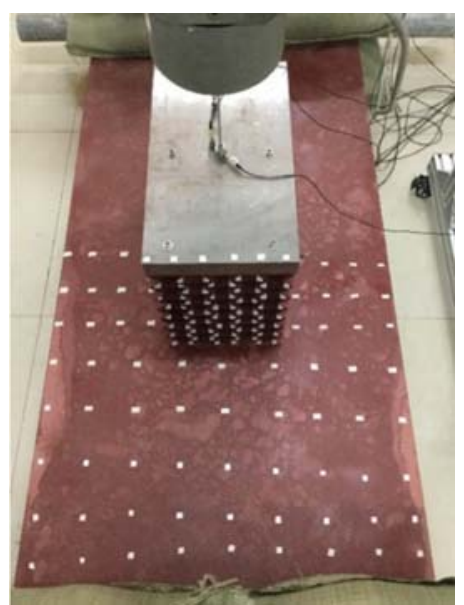

FIGURE 18: Layout of measuring points for modal test.

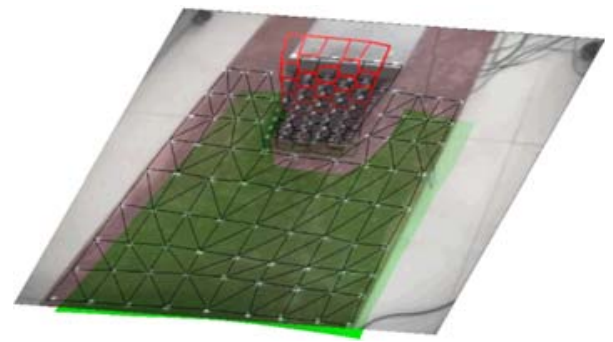

(a)

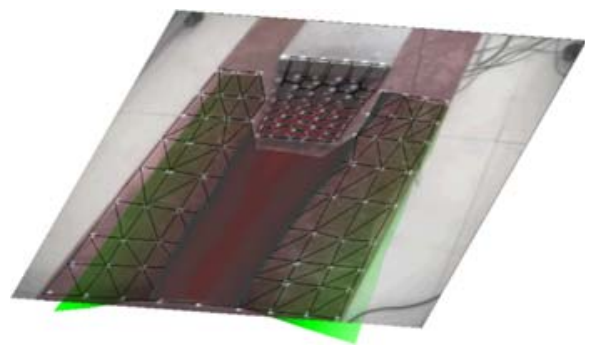

(b)

Figure 19: Two-node vertical mode shape of the control base: (a) mode shape of the auxetic cellular base and (b) mode shape of the steel grillage.

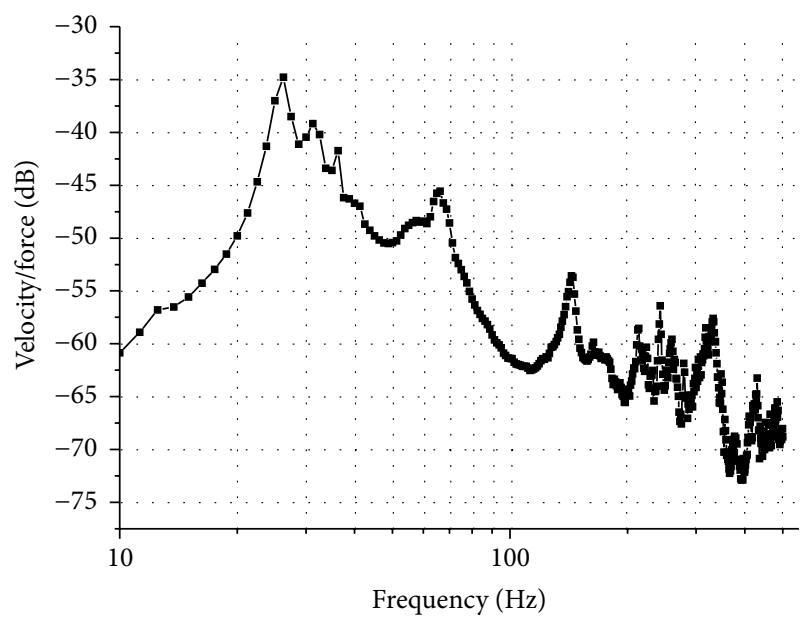

FIGURE 20: Average velocity response function of the control base (dB-Reference: $0 \mathrm{~dB}=1 \mathrm{~m} / \mathrm{s} / \mathrm{N}$ ).

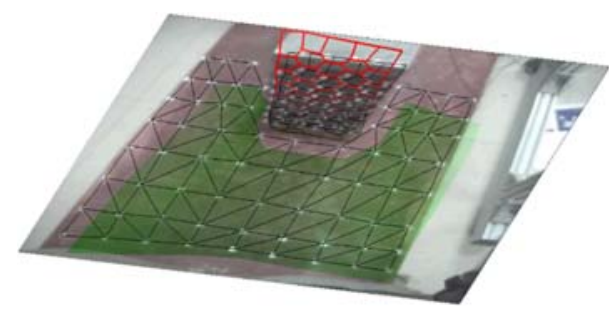

(a)

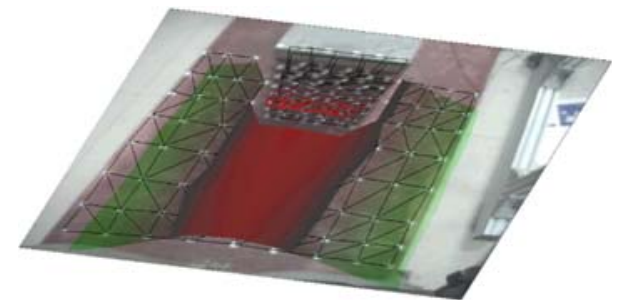

(b)

Figure 21: Two-node vertical mode shape of the verification base: (a) mode shape of the auxetic cellular base and (b) mode shape of the steel grillage.

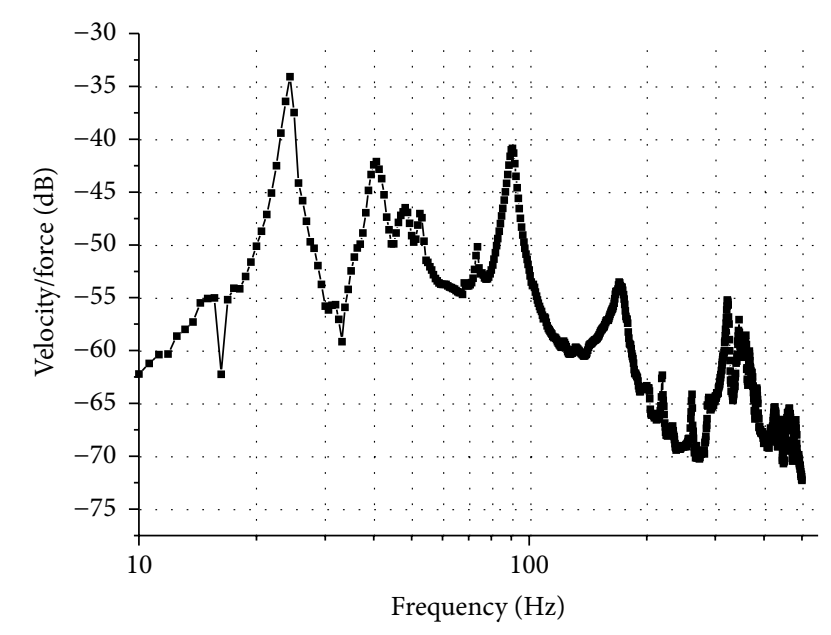

FIGURE 22: Average velocity response function of the verification base (dB-Reference: $0 \mathrm{~dB}=1 \mathrm{~m} / \mathrm{s} / \mathrm{N})$. 


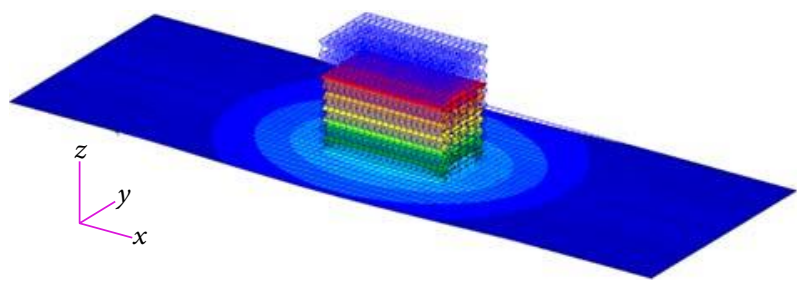

(a)

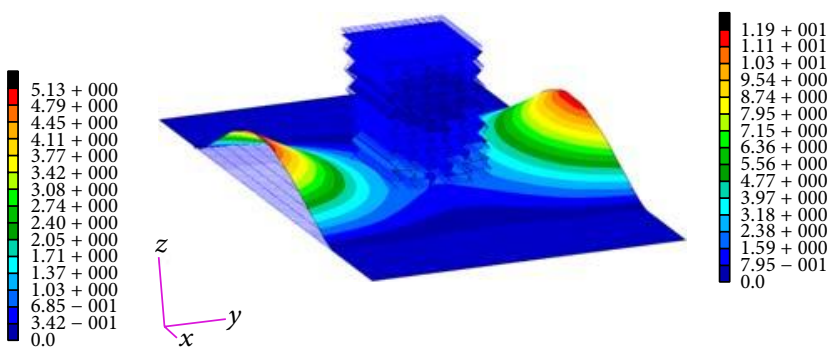

(b)

FIGURE 23: Two-node vertical mode shape of the control base with the FEM: (a) mode shape of the auxetic cellular base and (b) mode shape of the steel grillage.

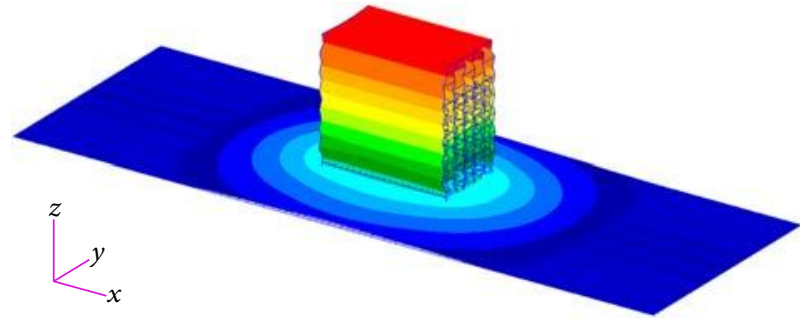

(a)

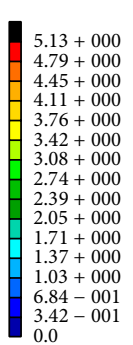

- 001

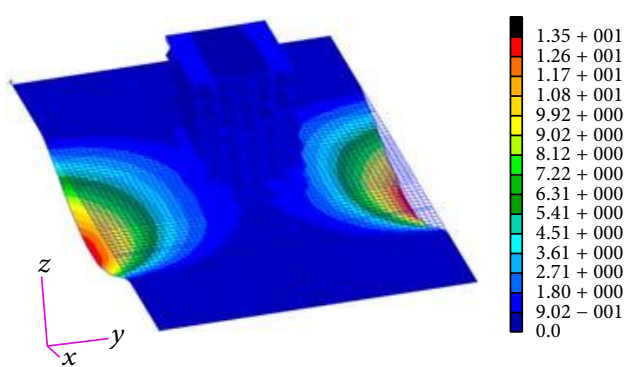

(b)

FIGURE 24: Two-node vertical mode shape of the verification base with the FEM: (a) mode shape of the auxetic cellular base and (b) mode shape of the steel grillage.

sandbags on the constraint conditions of the bases were eliminated. The mode shapes and vertical natural frequencies of the final models are shown in Figures 23 and 24 and Table 4. After the modification of FE models, the relative errors between the FEM and experimental results are very small, which ensures the accuracy of the numerical simulation. Moreover, these results also prove that the conclusion drawn in the static test is correct; that is, the vertical elastic stiffness of the verification base is bigger than that of the control base.

3.4. Frequency Response Test. The boundary conditions of the frequency response experiment correspond to those of the modal experiment (Figure 25). Besides the instruments mentioned above, accelerometers ( $B \& \mathrm{~K} 4366)$ and force sensors (5110) were used to collect the signals of different measuring points in the frequency domain. The block diagram of the excited and measured analysis system is shown in Figure 26. Five experiments were done for each base with five different exciting forces, ranging from $10 \mathrm{~N}$ to $50 \mathrm{~N}$ with the sweep bandwidth of 10 500 Hz. Figures 27 and 28 show the acceleration frequency response functions (FRF) of the two experimental bases with different exciting forces. With these data, vibration level difference of the bases was calculated and listed in Table 5. Computational results of acceleration FRF are shown in Figure 29.

Table 5 shows that increasing or decreasing the exciting force has slight effect on the vibration level difference, and the

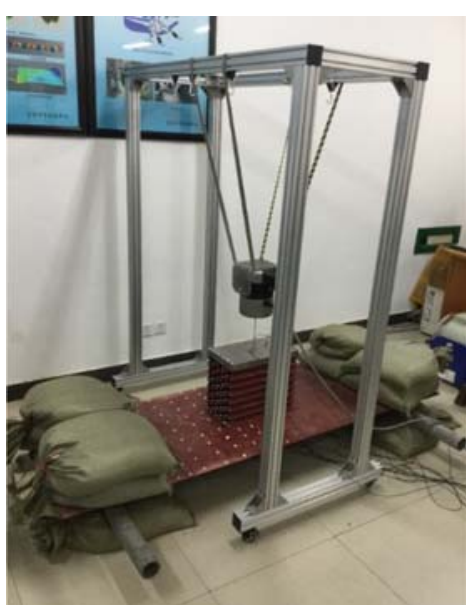

FIGURE 25: Frequency response experiment of the auxetic cellular base.

average values of vibration level difference of control base and verification base are $3.52 \mathrm{~dB}$ and $5.04 \mathrm{~dB}$, respectively. In Figure 29 , the computational results of vibration level difference are $3.24 \mathrm{~dB}$ and $5.56 \mathrm{~dB}$, respectively. For the control base, the relative error of the results between the FE model and experiment is 7.93\%; and for the verification base, it is $-9.35 \%$ (Table 6). It is worth noticing that the maximum amplitude of the exciting force of the electrodynamic shaker is $50 \mathrm{~N}$, and strong unstable responses were observed there. And when 
TABLE 4: Comparison of results between the experiment and modified FE models (Hz).

\begin{tabular}{|c|c|c|c|c|c|c|}
\hline & \multicolumn{3}{|c|}{$\begin{array}{l}\text { Two-node vertical natural frequencies of the } \\
\text { auxetic cellular base }\end{array}$} & \multicolumn{3}{|c|}{$\begin{array}{c}\text { Two-node vertical natural frequencies of } \\
\text { the steel grillage }\end{array}$} \\
\hline & Experiment & $\begin{array}{l}\text { Modified FE } \\
\text { models }\end{array}$ & Errors & Experiment & Modified FE models & Errors \\
\hline Control base & 66.25 & 66.77 & $-0.8 \%$ & 143.75 & 142.70 & $0.7 \%$ \\
\hline Verification base & 90.63 & 88.40 & $2.5 \%$ & 170 & 172.47 & $-1.4 \%$ \\
\hline
\end{tabular}

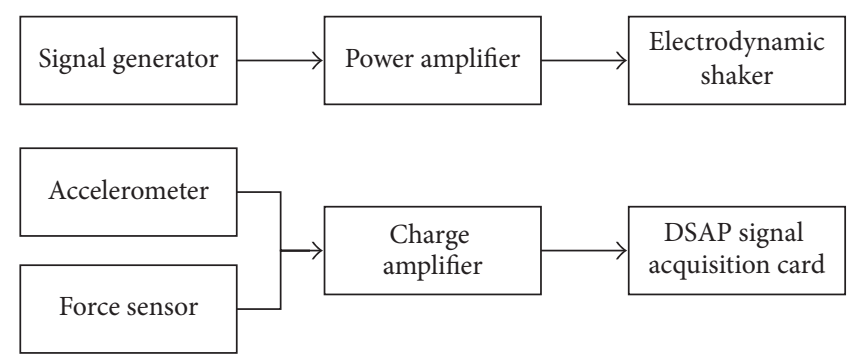

FIGURE 26: Block diagram of the excited and measured analysis system.

TABLE 5: Vibration level difference of the two bases for different exciting forces $(\mathrm{dB})$.

\begin{tabular}{lccccc}
\hline & $10 \mathrm{~N}$ & $20 \mathrm{~N}$ & $30 \mathrm{~N}$ & $40 \mathrm{~N}$ & $50 \mathrm{~N}$ \\
\hline Control base & 3.58 & 3.41 & 3.47 & 3.53 & 3.62 \\
Verification base & 4.79 & 5.21 & 5.19 & 5.05 & 4.97 \\
\hline
\end{tabular}

TABLE 6: Comparison of numerical and experimental results of the vibration level difference $(\mathrm{dB})$.

\begin{tabular}{lccc}
\hline & $\begin{array}{c}\text { Numerical } \\
\text { results }\end{array}$ & $\begin{array}{c}\text { Experimental } \\
\text { results }\end{array}$ & Relative error \\
\hline Control base & 3.24 & 3.52 & $7.93 \%$ \\
Verification base & 5.56 & 5.04 & $-9.35 \%$ \\
\hline
\end{tabular}

the exciting force was $10 \mathrm{~N}$, responses of the two bases were very small. Therefore accurate experimental results would be arrived at if we exclude these two conditions. Under such circumstances, the average values of vibration level difference of control base and verification base are $3.47 \mathrm{~dB}$ and $5.15 \mathrm{~dB}$, respectively. Compared with the FE results, the relative errors are $-6.6 \%$ and $-7.43 \%$, respectively. Good agreement between the experimental and calculation results was reached.

On the other hand, the comparison of the experimental and the optimal results obtained in Section 3.1 shows that the relative error between the results of the verification base and the optimal model is $11.5 \%$. Furthermore, in view of the vibration isolation performance of the bases, the verification base is better than the control base. These prove that the optimal model and results in this paper are correct and can be applied in the field of engineering design. As for the above-mentioned error, the reasons may lie in the following. (1) Limitations of experimental constraints and loading conditions: it is possible that during the test, the bases are not in a horizontal position. This will result in the deviation of the loading direction. (2) The limitation of the honeycomb dimension: discontinuous welding may exist in some portions, which will affect the propagation of vibrations. (3) The exact damping coefficients were not obtained in this paper. This leads to the differences of the response amplitudes between the FE and experimental models in resonance frequencies.

\section{Conclusions}

In this research, a light-weight vibration isolation base design was proposed based on auxetic reentrant hexagonal honeycombs. For the foldable (the aspect ratio of honeycombs is 2), equal-height reentrant hexagonal honeycombs, the effects of Poisson's ratio and relative density of these honeycombs on the dynamic performance of the novel base were studied numerically and experimentally.

(1) Compared with traditional base, the presented auxetic cellular base decreases the propagation of vibrations more efficiently and has lighter weight.

(2) By decreasing relative density and increasing Poisson's ratio of the honeycombs, the auxetic cellular base exhibits excellent vibration isolation performance.

(3) Computational models and results of shape and size optimization of the novel base were also presented. Experimental verification has been carried out through static, modal, and frequency response tests. The results of vibration level difference show close agreement between the numerical and experimental methods. 


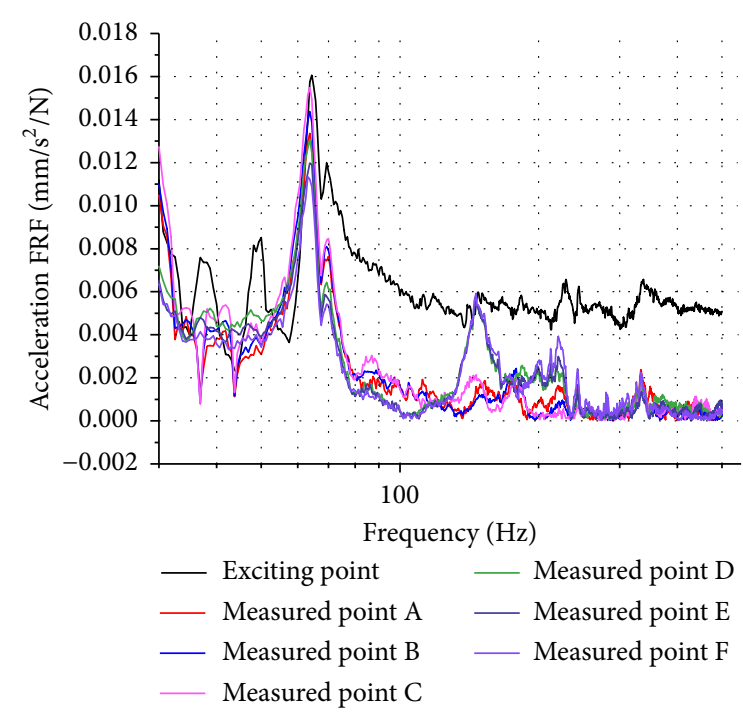

(a)

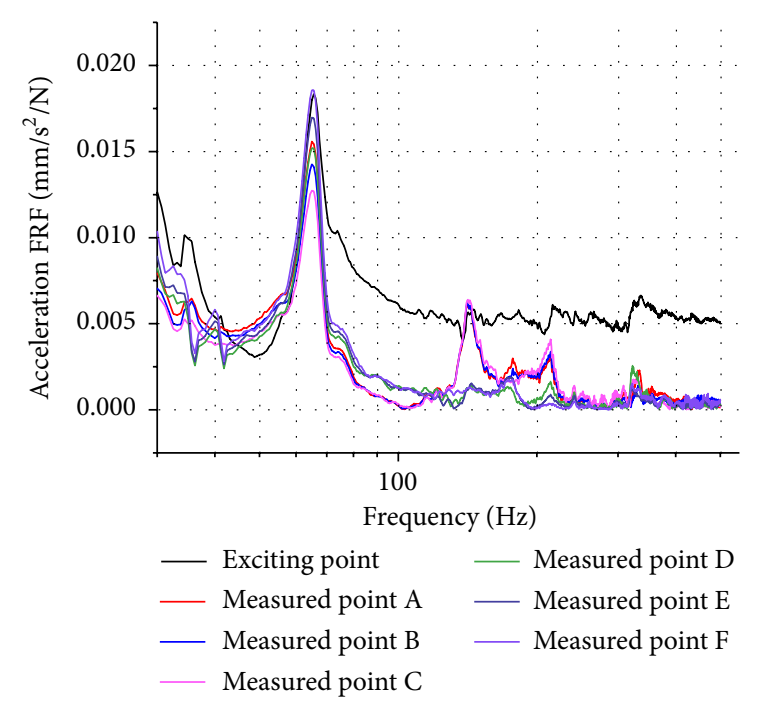

(c)

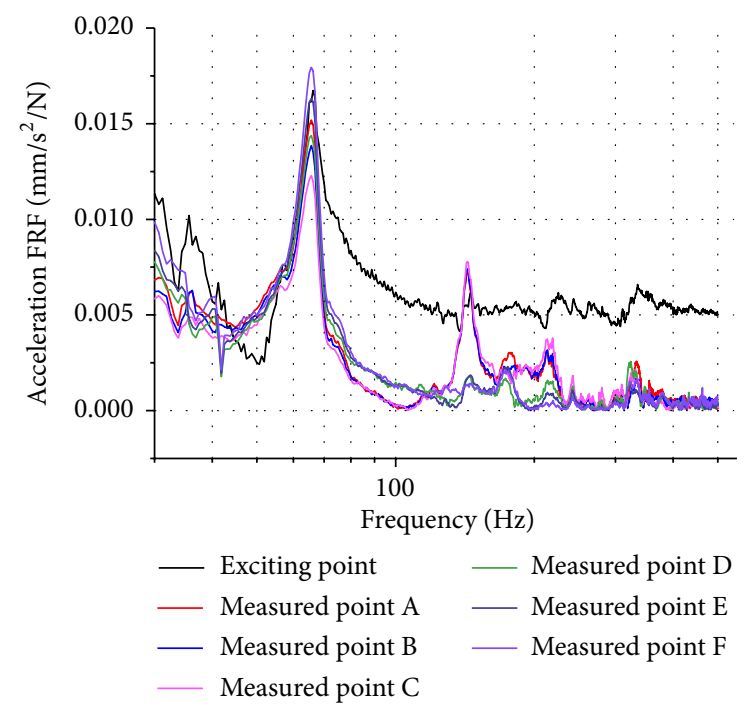

(b)

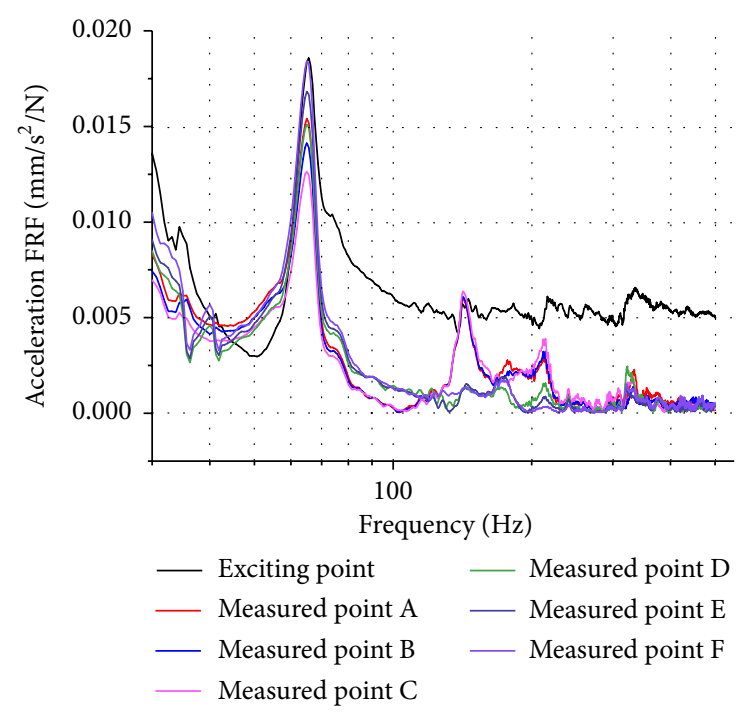

(d)

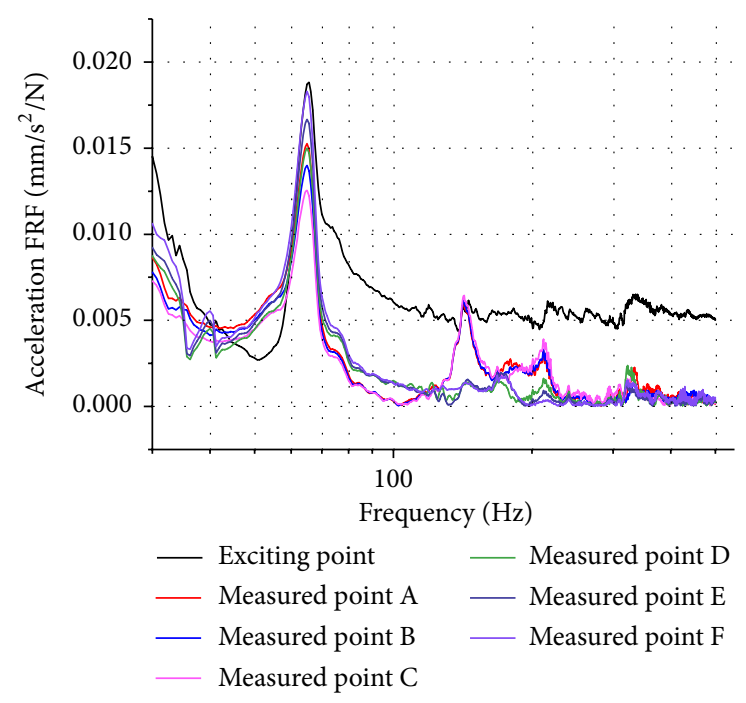

(e)

FIgURE 27: Acceleration FRF of the control base with different exciting forces: (a) $10 \mathrm{~N}$, (b) $20 \mathrm{~N}$, (c) $30 \mathrm{~N}$, (d) $40 \mathrm{~N}$, and (e) $50 \mathrm{~N}$. 


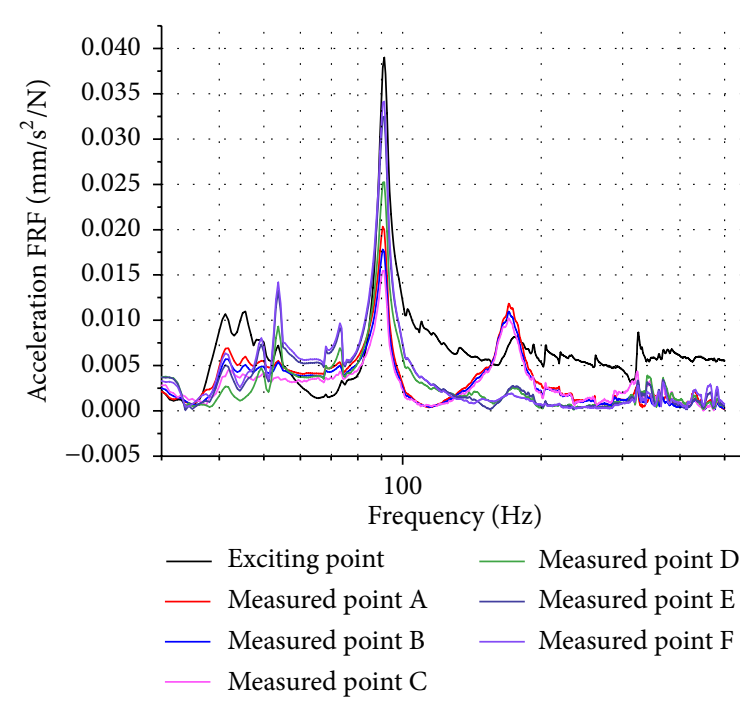

(a)

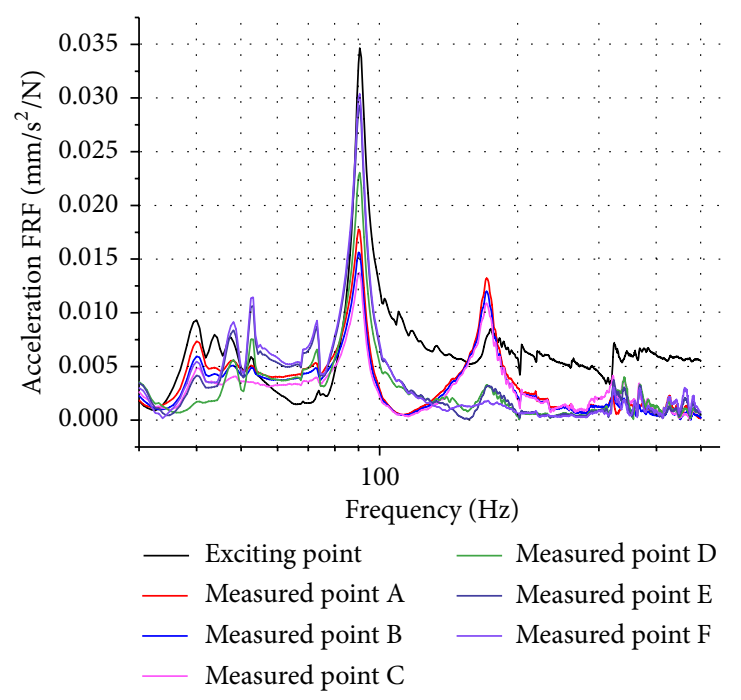

(c)

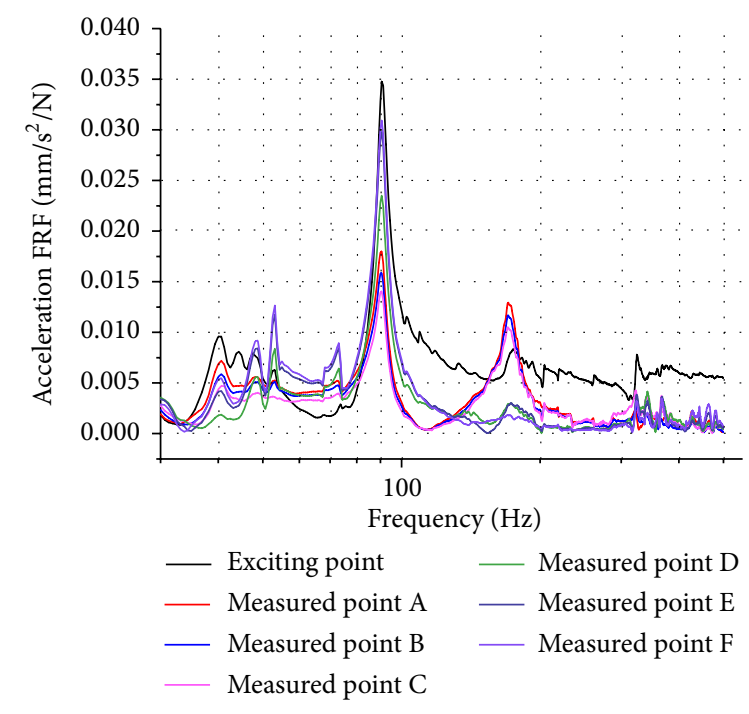

(b)

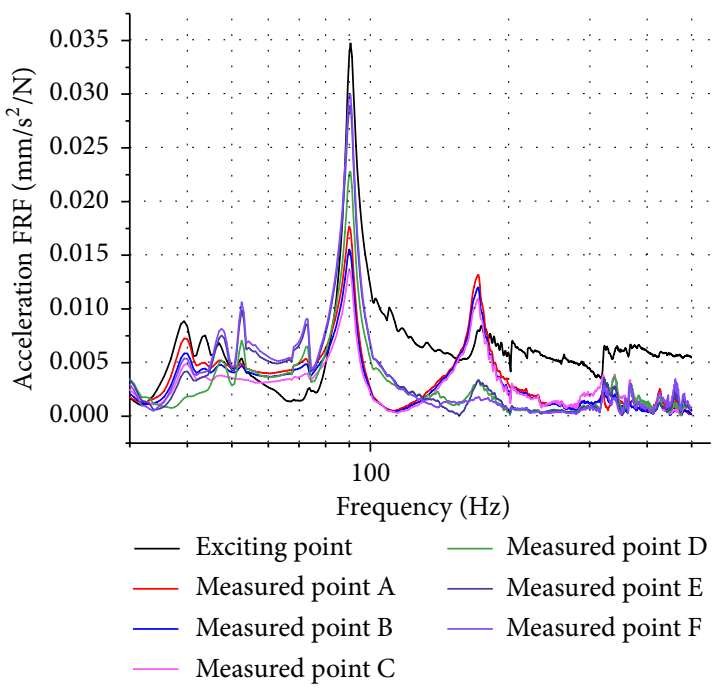

(d)

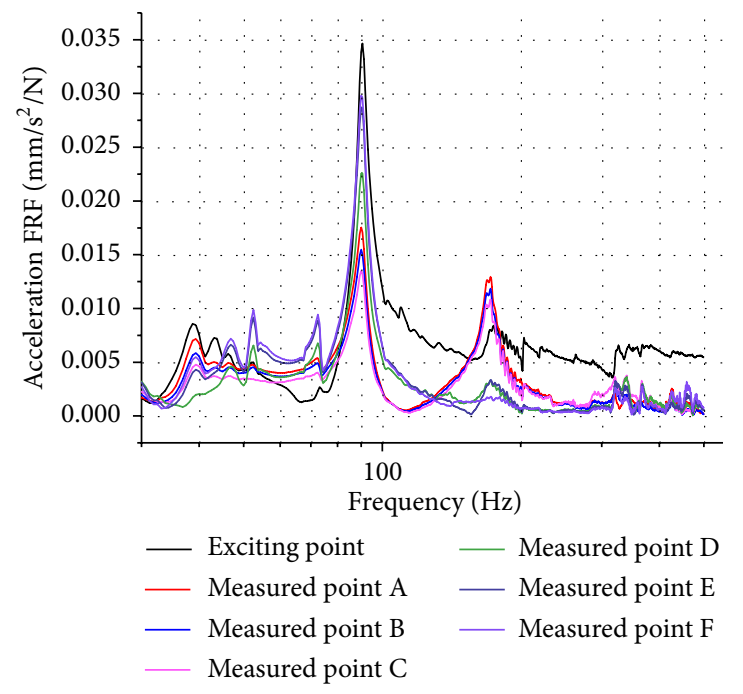

(e)

FIGURE 28: Acceleration FRF of the verification base with different exciting forces: (a) $10 \mathrm{~N}$, (b) $20 \mathrm{~N}$, (c) $30 \mathrm{~N}$, (d) $40 \mathrm{~N}$, and (e) $50 \mathrm{~N}$. 


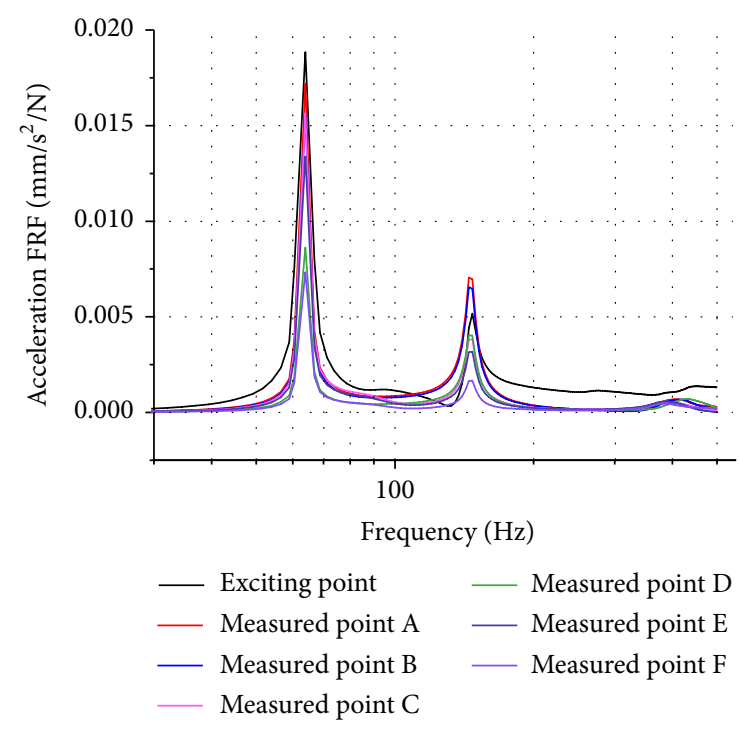

(a)

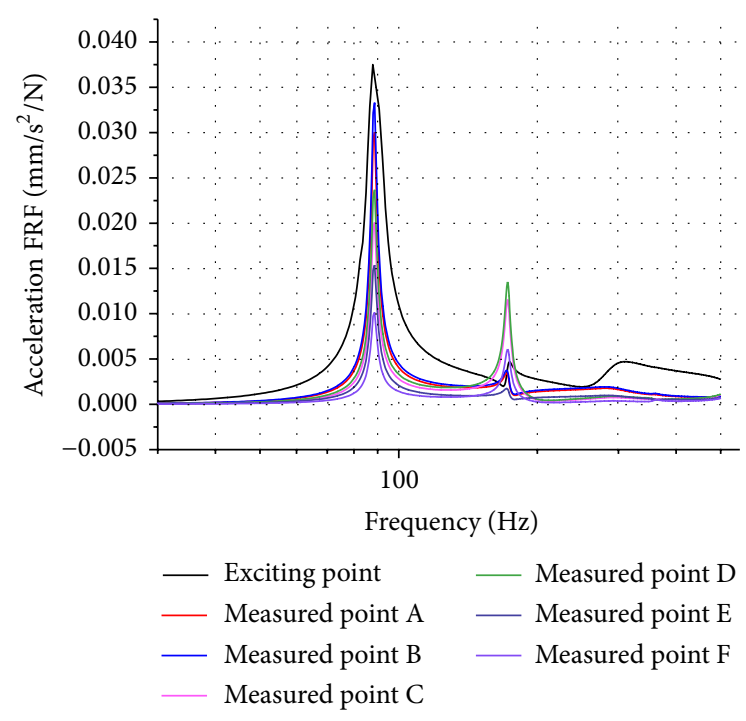

(b)

Figure 29: Acceleration FRF of the FE models: (a) the control base and (b) the verification base.

In the near future, the work presumably will focus on the effects of honeycomb shapes, dimensions, and arrangements on the vibration isolation performance of the auxetic cellular base. We believe that this novel base, which can be simply manufactured and easily adaptable to specific requirements, can be exploited in a great variety of industrial fields, considering also that the effective behavior of the auxetic cellular structure is scale-independent.

\section{Competing Interests}

The authors declare that they have no competing interests.

\section{Acknowledgments}

The support for this work, provided by the National Natural Science Foundation of China under Grant 51479115, is gratefully acknowledged.

\section{References}

[1] K. E. Evans, M. A. Nkansah, I. J. Hutchinson, and S. C. Rogers, "Molecular network design," Nature, vol. 353, no. 6340, pp. 124$125,1991$.

[2] J. N. Grima, R. Gatt, P.-S. Farrugia, A. Alderson, and K. E. Evans, "Auxetic cellular materials and structures," in Proceedings of the ASME International Mechanical Engineering Congress and Exposition (IMECE '05), pp. 489-495, Orlando, Fla, USA, November 2005.

[3] S. K. Bhullar, J. L. Wegner, and A. Mioduchowski, "Auxetic behavior of thermo-elastic layered plate," Journal of Engineering and Technology Research, vol. 2, no. 9, pp. 161-167, 2010.

[4] R. Lakes, "Advances in negative Poisson's ratio materials," Advanced Materials, vol. 5, no. 4, pp. 293-296, 1993.

[5] F. Scarpa, P. Pastorino, A. Garelli, S. Patsias, and M. Ruzzene, "Auxetic compliant flexible PU foams: Static and dynamic properties," Physica Status Solidi B, vol. 242, no. 3, pp. 681-694, 2005.

[6] J. N. Grima, D. Attard, R. Gaff, and R. N. Cassar, "A novel process for the manufacture of auxetic foams and for their re-conversion to conventional form," Advanced Engineering Materials, vol. 11, no. 7, pp. 533-535, 2009.

[7] J. N. Grima, D. Attard, R. N. Cassar, L. Farrugia, L. Trapani, and R. Gatt, "On the mechanical properties and auxetic potential of various organic networked polymers," Molecular Simulation, vol. 34, no. 10-15, pp. 1149-1158, 2008.

[8] J. N. Grima and K. E. Evans, "Auxetic behavior from rotating triangles," Journal of Materials Science, vol. 41, no. 10, pp. 31933196, 2006.

[9] C. He, P. Liu, and A. C. Griffin, "Toward negative poisson ratio polymers through molecular design," Macromolecules, vol. 31, no. 9, pp. 3145-3147, 1998.

[10] C. He, P. Liu, A. C. Griffin, C. W. Smith, and K. E. Evans, "Morphology and deformation behaviour of a liquid crystalline polymer containing laterally attached pentaphenyl rods," Macromolecular Chemistry and Physics, vol. 206, no. 2, pp. 233239, 2005.

[11] K. L. Alderson and K. E. Evans, "The fabrication of microporous polyethylene having a negative Poisson's ratio," Polymer, vol. 33, no. 20, pp. 4435-4438, 1992.

[12] K. L. Alderson, A. Alderson, G. Smart, V. R. Simkins, and P. J. Davies, "Auxetic polypropylene fibres-part 1: manufacture and characterisation," Plastics, Rubber and Composites, vol. 31, no. 8 , pp. 344-349, 2002.

[13] J. F. Clarke, R. A. Duckett, P. J. Hine, I. J. Hutchinson, and I. M. Ward, "Negative Poisson's ratios in angle-ply laminates: theory and experiment," Composites, vol. 25, no. 9, pp. 863-868, 1994.

[14] R. H. Baughman, J. M. Shacklette, A. A. Zakhidov, and S. Stafström, "Negative Poisson's ratios as a common feature of cubic metals," Nature, vol. 392, no. 6674, pp. 362-365, 1998.

[15] F. Scarpa and G. Tomlinson, "Theoretical characteristics of the vibration of sandwich plates with in-plane negative Poisson's 
ratio values," Journal of Sound and Vibration, vol. 230, no. 1, pp. 45-67, 2000.

[16] X.-W. Zhang and D.-Q. Yang, "A novel marine impact resistance and vibration isolation cellular base," Journal of Vibration and Shock, vol. 34, no. 10, pp. 40-45, 2015.

[17] R. S. Lakes and K. Elms, "Indentability of conventional and negative Poisson's ratio foams," Journal of Composite Materials, vol. 27, no. 12, pp. 1193-1202, 1993.

[18] A. Spagnoli, R. Brighenti, M. Lanfranchi, and F. Soncini, "On the auxetic behaviour of metamaterials with re-entrant cell structures," Procedia Engineering, vol. 109, pp. 410-417, 2015.

[19] W. L. Azoti, Y. Koutsawa, N. Bonfoh, P. Lipinski, and S. Belouettar, "Analytical modeling of multilayered dynamic sandwich composites embedded with auxetic layers," Engineering Structures, vol. 57, pp. 248-253, 2013.

[20] M. Mir, M. N. Ali, J. Sami, and U. Ansari, "Review of mechanics and applications of auxetic structures," Advances in Materials Science and Engineering, vol. 2014, Article ID 753496, 17 pages, 2014.

[21] K. E. Evans and K. L. Alderson, "Auxetic materials: the positive side of being negative," Engineering Science \& Education Journal, vol. 9, no. 4, pp. 148-154, 2000.

[22] A. Alderson, J. Rasburn, S. Ameer-Beg, P. G. Mullarkey, W. Perrie, and K. E. Evans, "An auxetic filter: a tuneable filter displaying enhanced size selectivity or defouling properties," Industrial and Engineering Chemistry Research, vol. 39, no. 3, pp. 654-665, 2000.

[23] J. B. Choi and R. S. Lakes, "Design of a fastener based on negative Poisson's ratio foam," Cellular Polymers, vol. 10, no. 3, pp. 205-212, 1991.

[24] A. Alderson and K. L. Alderson, "Auxetic materials," Proceedings of the Institution of Mechanical Engineers, Part G, vol. 221, no. 4, pp. 565-575, 2007.

[25] C. Dascalu, G. Bilbie, and E. K. Agiasofitou, "Damage and size effects in elastic solids: a homogenization approach," International Journal of Solids and Structures, vol. 45, no. 2, pp. 409430, 2008.

[26] Y. Prawoto, "Seeing auxetic materials from the mechanics point of view: a structural review on the negative Poisson's ratio," Computational Materials Science, vol. 58, pp. 140-153, 2012.

[27] F. Scarpa, P. Panayiotou, and G. Tomlinson, "Numerical and experimental uniaxial loading on in-plane auxetic honeycombs," Journal of Strain Analysis for Engineering Design, vol. 35, no. 5, pp. 383-388, 2000.

[28] F. Scarpa, F. C. Smith, B. Chambers, and G. Burriesci, "Mechanical and electromagnetic behaviour of auxetic honeycomb structures," Aeronautical Journal, vol. 107, no. 1069, pp. 175-183, 2003.

[29] J. N. Grima, E. Manicaro, and D. Attard, "Auxetic behaviour from connected different-sized squares and rectangles," Proceedings of the Royal Society of London, Series A: Mathematical, Physical and Engineering Sciences, vol. 467, no. 2126, pp. 439458, 2011.

[30] E. Chetcuti, B. Ellul, E. Manicaro et al., "Modeling auxetic foams through semi-rigid rotating triangles," Physica Status Solidi B, vol. 251, no. 2, pp. 297-306, 2014.

[31] M. S. Rad, Z. Ahmad, and A. Alias, "Computational approach in formulating mechanical characteristics of 3D star honeycomb auxetic structure," Advances in Materials Science and Engineering, vol. 2015, Article ID 650769, 11 pages, 2015.
[32] J. N. Grima, R. Gatt, A. Alderson, and K. E. Evans, "On the potential of connected stars as auxetic systems," Molecular Simulation, vol. 31, no. 13, pp. 925-935, 2005.

[33] L. J. Gibson and M. F. Ashby, Cellular Solids: Structure and Properties, Pergamon Press, London, UK, 1988.

[34] I. G. Masters and K. E. Evans, "Models for the elastic deformation of honeycombs," Composite Structures, vol. 35, no. 4, pp. 403-422, 1996.

[35] K. E. Evans, A. Alderson, and F. R. Christian, "Auxetic twodimensional polymer networks. An example of tailoring geometry for specific mechanical properties," Journal of the Chemical Society, Faraday Transactions, vol. 91, no. 16, pp. 2671-2680, 1995.

[36] Z.-X. Lu, X. Li, Z.-Y. Yang, and F. Xie, "Novel structure with negative Poisson's ratio and enhanced Young's modulus," Composite Structures, vol. 138, pp. 243-252, 2016.

[37] Y. A. Rossikhin and M. V. Shitikova, "New approach for the analysis of damped vibrations of fractional oscillators," Shock and Vibration, vol. 16, no. 4, pp. 365-387, 2009. 


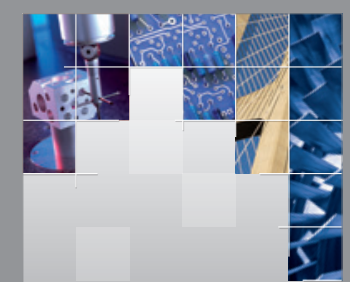

\section{Enfincering}
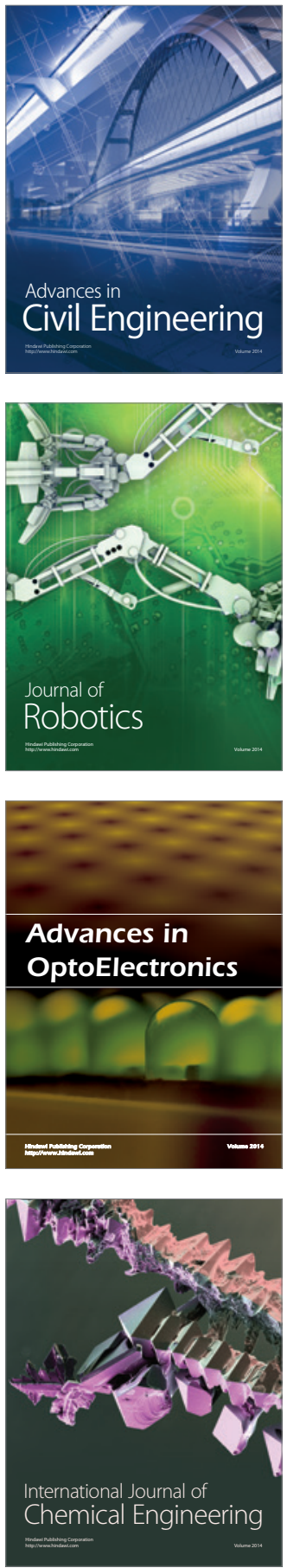

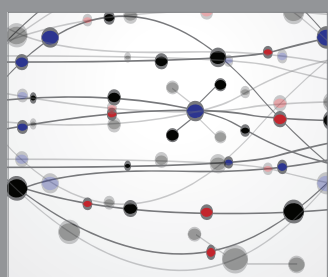

The Scientific World Journal

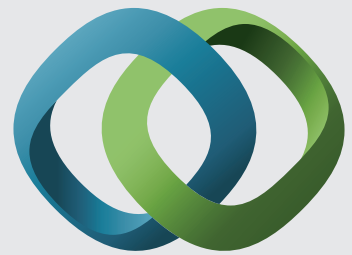

\section{Hindawi}

Submit your manuscripts at

http://www.hindawi.com
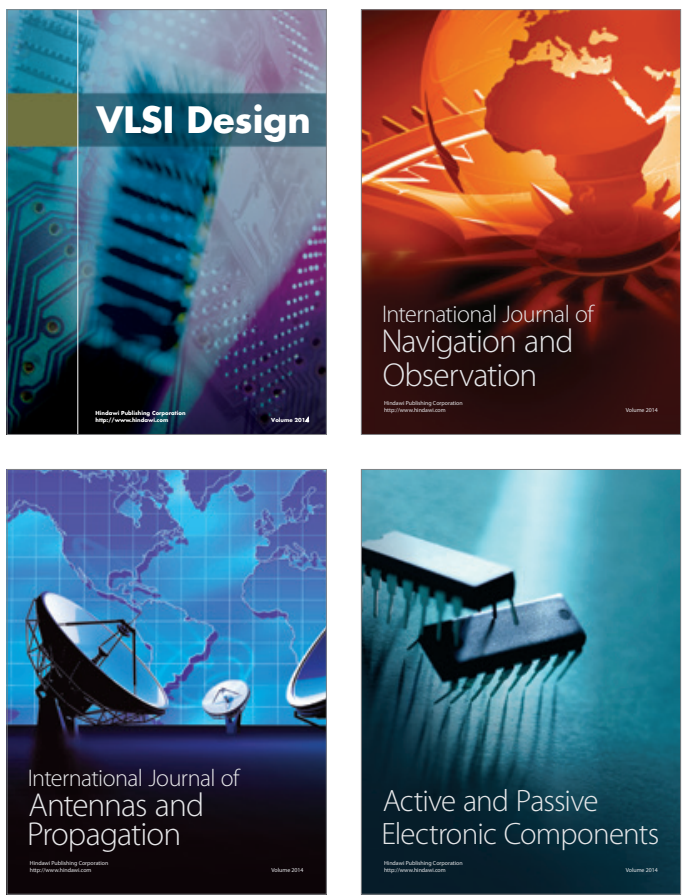
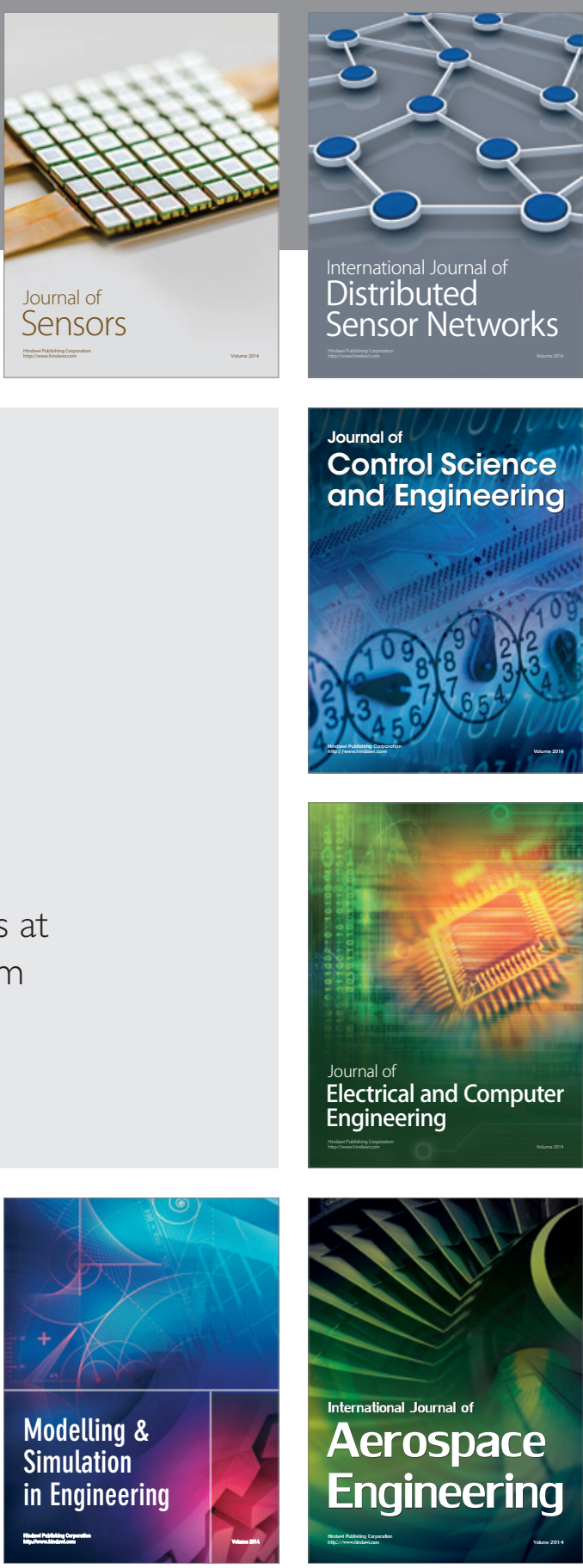

International Journal of

Distributed

Sensor Networks

Journal of

Control Science

and Engineering
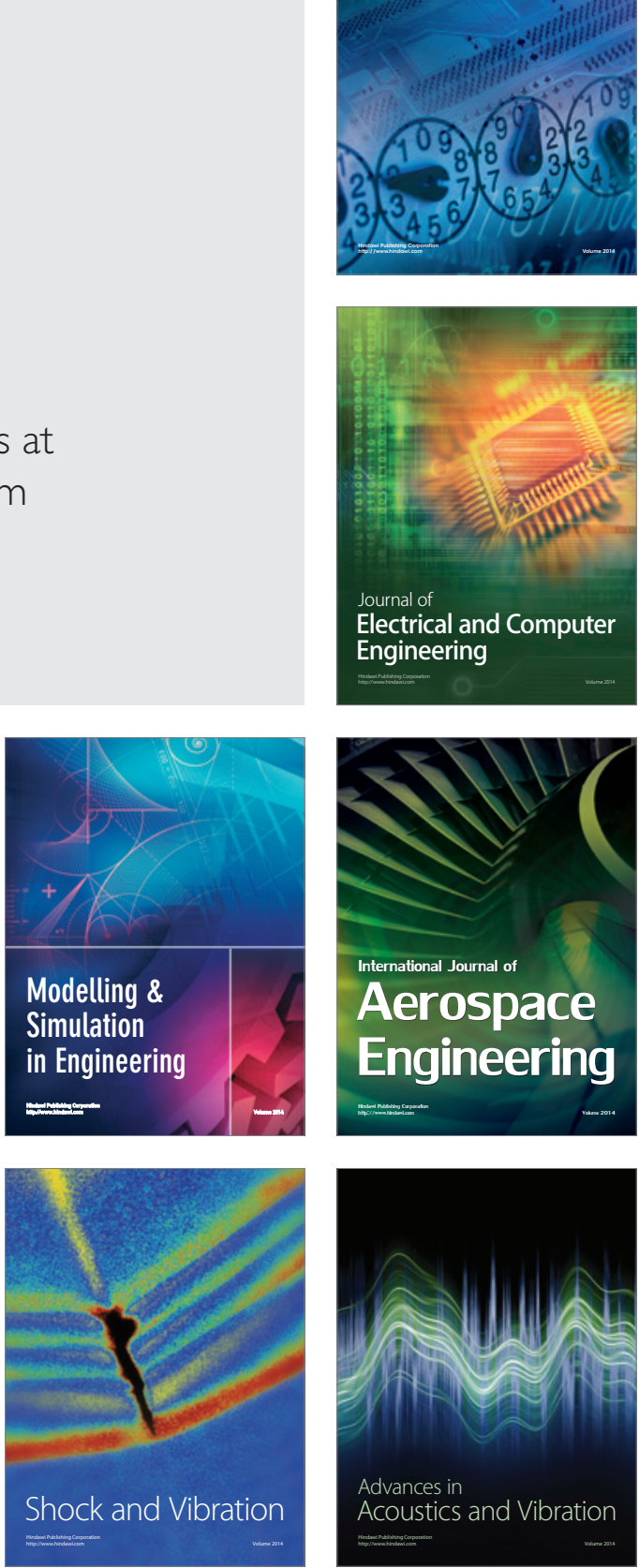